\title{
Assessing Processes of Change in Psychological Interventions: The Process-Based Assessment Tool (PBAT)
}

\author{
Joseph Ciarrochi
}

Institute of Positive Psychology and Education, Australian Catholic University, Sydney, Australia

\section{Baljinder Sahdra}

Institute of Positive Psychology and Education, Australian Catholic University, Sydney, Australia

\author{
Stefan. G. Hofmann
}

Department of Clinical Psychology, Philipps-University Marburg, Germany, and Department of Psychological and Brain Sciences, Boston University, Boston, USA

$$
\text { Steven C. Hayes }
$$

Behavior Analysis Program, Department of Psychology, University of Nevada, Reno, USA

\section{Author Note}

Correspondence concerning this article should be addressed to. Professor Joseph Ciarrochi, Institute for Positive Psychology and Education, Australian Catholic University. North Sydney, NSW, 2060 Joseph.ciarrochi@acu.edu.au

We have no conflicts of interest to disclose

Joseph Ciarrochi: https://orcid.org/0000-0003-0471-8100 Baljinder Sahdra: https://orcid.org/0000-0001-5064-7783 Stefan G. Hofmann: https://orcid.org/0000-0002-3548-9681 Steven C. Hayes: https://orcid.org/0000-0003-4399-6859

Keywords: Process-based therapy. PBT. Intervention. Experience sampling; Extended-Evolutionary Meta-Model; need satisfaction and thwarting; mental health; anxiety; stress; anger; depression; well-being 


\begin{abstract}
The "protocols for syndromes" approach to evidence-based psychological intervention has failed the test of scientific progressivity. Process-based therapy provides an alternative model that is focused on treatment elements that target biopsychosocial processes of relevance to individual treatment goals. That shift in focus requires new, more integrative and idionomic models that identify key processes of change, using high temporal density measurement applied at the level of the person. Standard measurement validation approaches are inadequate to this challenge. The present study develops and provides a preliminary validation of a process-based assessment tool (PBAT) -- an item pool meant for intensive longitudinal clinical assessment. Developed using the Extended-Evolutionary MetaModel of PBT and evaluated using an evolutionary algorithm appropriate for the evaluation of individual items, we administered the PBAT online to a representative sample of 598 participants (290 male; 302 female; 6 unidentified. $M_{a g e}=32.6$ ). Analyses revealed that the PBAT distinguishes between positive and negative processes, links in theoretically coherent ways to need satisfaction and thwarting, and links to clinically relevant outcomes of sadness, anger, anxiety, stress, lack of social support, vitality, and health. The PBAT provides a beginning step towards developing a process-based tool that allows clinicians and researchers to select individual items or sets of items for individual-focused idionomic research and practice.
\end{abstract}




\section{Assessing Processes of Change in Psychological Interventions: The Process-Based Assessment Tool (PBAT)}

The ultimate scientific purpose of diagnosing psychiatric syndromes is to identify their etiology, to understand the course of pathological processes, and to identify and understand clinically meaningful responses to intervention.

Unfortunately, there is wide agreement that little progress is being made on these issues. Despite its importance, research suggests the utility of traditional diagnosis in improving clinical outcomes is still minimal (Mullins-Sweatt et al., 2016). Etiological and process knowledge linked to syndromes is similarly weak, leading even the developers of syndromal diagnosis (Kupfer et al., 2002) to worry that research on the current diagnostic system in this area may "never be successful" (p. xix).

These weaknesses have a practical, not merely a conceptual cost. The rate of mental and behavioral health problems has remained persistently high (Moffitt et al., 2010; Richter et al., 2019), despite over a half century of research on clinical interventions linked to psychiatric syndromes. Indeed, meta-analyses suggest that the effectiveness of psychotherapy interventions is not improving (Ljótsson et al., 2017). Researchers commonly evaluate interventions in a "horse race" model, where they pit one package against another in a randomized-control trial. Many therapies receive moderate evidence of support with differences between therapies being absent or small (Cuijpers et al., 2013). Nevertheless, complex treatment packages have proliferated, often with unknown, unclear, or vastly overlapping targeted processes of change. It has become impossible to be expert at even a small subset of methods that claim to be evidence-based.

In acknowledgement of this palpable lack of progress, in the last decade there has been a sharp turn toward the direct examination of processes of change that are 
linked to the goals of intervention (Hayes, Hofmann, \& Ciarrochi, 2020a, 2020b; Hofmann \& Hayes, 2019). The National Institute of Mental Health reoriented its research portfolio toward Research Domain Criteria (RDoC; Insel et al., 2010) -studying processes that may help explain the neurodevelopmental features presumed to be the underlying mechanisms of mental health problems. Unfortunately the strong pre-commitment of RDoC to the role of biophysiological mechanisms (Vaidyanathan et al., 2020) undermined this program both scientifically and practically since there was and still is "no compelling evidence for the viability of reducing mental disorders to unique biological abnormalities, both in terms of enhanced etiological understanding and of improving the effectiveness of interventions" (Borsboom et al., 2018,p. 2).

Psychological science task forces have also sought to build consensus for a process focus (Hayes et al., 2021). For example, the report of the InterOrganizational Task Force on Cognitive and Behavioral Psychology Doctoral Education (Klepac et al. 2012) called for more focus on "understanding the processes that determine behavior maintenance and change" (p. 693). Similarly, the Association for Contextual Behavioral Science (ACBS) Task Force on Strategies and Tactics of Contextual Behavioral Science Research (Hayes et al. 2021) called for more "research to identify processes of change" (p. 176) and "more longitudinal measurement that situates a psychological event in a behavioral stream and the context in which that stream occurs" (p. 175).

\section{From Trademarked Packages to Evidence-based Process}


Process-based therapy (PBT; Hayes \& Hofmann, 2018) reflects these same trends. Not a new therapy, but a new approach to describing evidence-based therapy, PBT can be defined as the "contextually specific use of evidence-based processes linked to evidence-based procedures to help solve the problems and promote the prosperity of particular people" (Hofmann \& Hayes, 2019, p. 38). We define processes of change as theory-based, dynamic, progressive, contextually bound, modifiable, and multilevel changes or mechanisms that occur in predictable empirically established sequences oriented toward desirable outcomes (Hayes, Hofmann, Ciarrochi,, 2020a; Hofmann \& Hayes, 2019). Said in another way, processes of change are biopsychosocial sequences that researchers have shown to be functionally important pathways toward meeting the goals of those receiving an intervention.

Unlike a syndromal approach, which starts with topographical features and hopes to find functionally important features, a process-based approach starts from the end and works backwards, constructing measurement and case analysis from elements known to be functionally important. This process-based approach could lead rapidly to greater clinical utility in the form of greater efficiency and effectiveness (Hayes, Hofmann, \& Ciarrochi, 2020a,2020b).

To explore these opportunities fully, however, we need new ways of measuring and analysing processes. Current approaches to the assessment of processes of change have emphasized self-report scales that are said to measure latent theoretical constructs and are validated using classical psychometrics. A change in tactics is essential because when classic psychometrics are applied to the practical world of treating a specific client in a specific context a lethal statistical problem reveals itself. 


\section{The Ergodic Error}

Assessing processes of change in groups and applying these processes to individuals requires sensitivity to changes within individual people. The traditional psychometrician uses normative statistical assumptions to examine consistencies among collections of individuals, intending to apply findings from the group to everyone. Mathematically, these two approaches can be contradictory because the set of restrictive conditions under which inter-subject variability can properly model intra-subject variability are impossible to meet in clinical behavioral science.

Physicists have long known that the assessment of collections of elements in space correspond to the measurement of these elements over time only under certain "ergodic" conditions. Ludwig Holzmann developed the concept in his work in statistical mechanics in the 1870's (Ashley, 2015), but it did not become universally accepted in the physical sciences until Birkoff (1931) and von Neumann (1932) provided independent mathematical proof of the ergodic theorem. It has been accepted science over the near century since.

Molenaar (2004) realized that if different spatial locations are mathematically analogous to different people and temporal measurement applies to changes within a person then the ergodic theorem also dramatically limits the conditions under which we can apply normative assumptions to individual concepts tested using classic statistics in psychology. Specifically, the ergodic theorem demands that for such applications to be mathematically valid, there must first be no mean or variance changes within persons over time and secondly, each person in the population must obey the same dynamic model (Molenaar, 2013). Said more concretely, to be ergodic the mean and variance of a feature must be identical both for all cross-sectional collections of persons, and for each person over time (Gates, Chow, \& Molenaar, in 
press). These severe stationarity and homogeneity assumptions automatically eliminate processes of change as legitimate topics to be tested using classical normative statistics, if the goal is to apply that knowledge, even probabilistically, to particular people (Fisher et al., 2018; Rabinowitz \& Fisher, 2020).

While this realization disrupts applied psychology, we can avoid the ergodic error by an "idionomic" approach (Hayes \& Hofmann, 2021) that first validates concepts idiographically based on relationships established against the background of intrasubject variability alone, and then gathers these relations into nomothetic generalizations, provided doing so illuminates idiographic information without distortion (Gates \& Molenaar, 2012).

\section{Creating a Model of Processes of Change}

There are other difficulties to be overcome beyond avoidance of the ergodic error when developing measures with a PBT focus. Unlike syndromally focused measures, measures of broadly focused processes of change need to be linked to a wide range of outcomes that are relevant to individual goals. Furthermore, because a wide range of processes could apply to a particular goal for a particular purpose, there must be a way to constrain these to a manageable problem space and to find an agreeable descriptive approach to promote consilience of findings across studies.

One proposed solution to this second set of difficulties has been to nest models of processes of change under the best-established theory available within life science, namely, evolutionary theory. Process-based therapy has embraced this approach with its "Extended Evolutionary Meta-Model" (EEMM) of processes of change (Hayes et al., 2019; Hayes, Hofmann, \& Ciarrochi, 2020a). The EEMM proposes that models of broadly applicable processes of change should specify how positive or negative features of variation, selection, retention, and contextual fit are 
reflected in key processes of change, approached in a multi-dimensional and multilevel evolutionary fashion. "Variation" refers to the degree of needed breadth and flexibility of processes that can be deployed to accomplish individual purposes; "selection" refers to the detection of relatively successful or unsuccessful deployment of skills or processes; "retention" refers to the maintenance of specific variants of processes; "context" refers to sensitivity to the internal and external situational and historical features that are predictive of success or failure for a given instance.

The EEMM suggests that we can apply these four essential and readily definable features of evolving systems to existing processes of change, organized into overall models by considering a broad set of psychological dimensions including affect, cognition, attention, self, motivation, and overt behavior and by examining additional dimensions occurring at the sociocultural and biophysiological levels of analysis. Because the defining nature of specific dimensions and levels of selection are empirical matters, the EEMM does not propose to establish hard dimensional or level of analysis boundaries, but adds these additional concepts based on their common occurrence in the literature on processes of change (Hayes, Hofmann, Ciarrochi,, Chin, \& Baljinder, 2020), to promote breadth of application and analysis.

The EEMM suggests that "each identified dimension can be functionally measured, using multiple methods, and in a way that fosters successful functional analysis", cautioning that measures need to be "valid at the individual level"; and that it be empirically known "the extent to which intervention outcomes are due to various change dimensions at the idiographic level" (Hayes et al., 2021, all quotes are p. 179).

\section{Creating Idionomic Process Measures}


The final key area of practical difficulty is resolving how to develop and evaluate measures that fit these statistical and practical constraints once we acknowledge that classical psychometrics and group comparative approaches contain an irresolvable ergodic error. While we may use idionomic methods to develop such measures, no one has yet worked out precisely how to do so. In part the immediate barrier is practical. It seems possible to generate, say, self-report items that would be tested in high-density longitudinal idiographic networks of processes of change that target common outcomes (Hofmann et al., 2020), retaining items that appear frequently and prominently in clinical work both before and after intervention when evaluated using idionomic methods. However, these methods often require 40 or more longitudinal assessments in each phase typically spread out over several weeks(Fisher et al., 2017; Gates \& Molenaar, 2012). Thus the assessment burden is considerable and grows as possible new items are added.

The present study attempted to address that problem by developing and providing a preliminary evaluation of the Process-Based Assessment Tool (PBAT). The PBAT is not a scale -- it is an item pool meant for idionomic use. The end goal of the study was to create and validate preliminary items that could then be used to study within-person processes of change, such as in daily diary studies or clinical studies using intensive repeated measures.

We derived PBAT items from the EEMM (Hayes, Hofmann, \& Ciarrochi, 2020a), with the goal of staying sufficiently close to multi-dimensional and multi-level evolutionary concepts that items would transtheoretical and usable by practitioners of any therapeutic orientation that is willing to see behavioral and psychological science through the lens of evolution. Because processes of change are functionally defined, we linked items to the "selection" column of the EEMM by considering evidence on 
human needs or yearnings, such as those suggested by self-determination theory (Ryan \& Deci, 2017) or psychological flexibility (Hayes, 2019). To address the biophysiological level, we added health items. We also added items specifically focused on variation and retention. Positively and negatively worded items were used for each modelled dimension because satisfying and thwarting goals or needs are distinguishable (Chen et al., 2015). In line with existing practice in EMA approach (Nezlek, 2012), we focused items on behavior, rather than content of traits, beliefs, thoughts, schemas, or aspects of character, as is common in many process measures. The focus on clinically relevant psychological actions was intended to make the measure relevant across theoretical orientations and to help focus the therapist on clear targets for intervention.

There is no well agreed up method for vetting single items for experience sampling methods. A traditional psychometric approach, such as factor analysis or reliability analysis, is poorly suited for this task because such methods assess the quality of items in terms of item consistency with an inferred latent construct based on inter-item correlations. To test a set of individual items, we need methods that allow items to succeed in competition with other items. In the present study, we used an evolutionary algorithm that allowed specific items to compete for success in predicting outcomes (Kursa et al., 2010) and then retained specific items based on overall success in multiple iterations of the evolutionary algorithm.

We tested three hypotheses. In keeping with research that enhancing and thwarting underlying psychological purposes are distinct processes (Bartholomew et al., 2011; Ryan \& Deci, 2017), we expected positive items would correlate moderately with other positive items, as would negative items, but positive and negative items would correlate less well (Hypothesis 1). We further expected PBAT 
items to link in theoretically coherent ways to the satisfaction or thwarting of underlying purposes (Hypothesis 2), as well as to clinically relevant outcomes of sadness, anger, anxiety, stress, lack of social support, vitality, and health (Hypothesis 3).

\section{Method}

\section{Participants and design}

We purchased a nationally representative American sample of 598 participants (290 males; 302 females; 6 unidentified) from Qualtrics. Participants completed an on-line, anonymous survey in exchange for points they received from the survey company, which they could redeem for merchandise (directly from the company). We designed the survey so that participants were required to enter responses to the questions, resulting in a $100 \%$ completion rate. The mean age of the sample was $32.6(S D=10.32)$.

\section{Measures}

\section{Process-Based Assessment Tool measure}

To develop the content of the items, we formed a theoretically diverse expert panel. This panel included Steven C. Hayes (expert in Acceptance and Commitment Therapy), Stefan G. Hofmann (expert in Cognitive Behavioral Therapy), Louise Hayes (expert in youth and adolescence), Baljinder Sahdra (expert in methodology and social psychology), Joseph Ciarrochi (expert in Positive Psychology and Acceptance and Commitment Therapy), Ann Bailey (expert in Psychodynamic Therapy), Frank Deane (Expert in Cognitive and Behavioral Therapy), and Robert Brockman (Expert in Schema Therapy). The panel worked through several revisions of the measure. The core goal was simplicity and theoretical clarity. We revised items 
that were ambiguous in terms of their dimensions or evolutionary targets. In the end, all items were approved by every member of the team.

Participants were presented with 21 statements. Items were designed to permit use with a specific temporal focus. In the present study, "During the last week," was added to items. A sample item was "During the last week, I struggled to connect with the moments in my day-to-day life." The full item pool is shown in Table 1. All items were rated on a 100-point touch-based slider, ranging from 0 (strongly disagree) to 100 (strongly agree). We chose a physical scale with such a wide range, in contrast to typical 5 or 7 point numerical scales, because we assumed that even small changes to clinically-relevant behaviour can be significant and because subsequent use of the items in idionomic research would depend on within respondent variability, which would be enhanced by a slider but needlessly reduced by a numerical scale, in which participants could easily remember past responses and potentially respond based on consistency rather than on current behavior. A practitioner-friendly version of the scale is available in the Appendix.

Table 1: Items in the PBAT

\begin{tabular}{|l|l|l|}
\hline Process Target & \multicolumn{1}{|c|}{ Negative Behavior } & \multicolumn{1}{c|}{ Positive behavior } \\
\hline Variation & $\begin{array}{l}\text { I felt stuck and unable to change } \\
\text { my ineffective behavior. }\end{array}$ & $\begin{array}{l}\text { I was able to change my behavior, } \\
\text { when changing helped my life }\end{array}$ \\
\hline $\begin{array}{l}\text { Selection of Affect / } \\
\text { Yearning to Feel }\end{array}$ & $\begin{array}{l}\text { I did not find an appropriate outlet } \\
\text { for my emotions }\end{array}$ & $\begin{array}{l}\text { I was able to experience a range } \\
\text { of emotions appropriate to the } \\
\text { moment }\end{array}$ \\
\hline $\begin{array}{l}\text { Selection of Cognition / } \\
\text { Yearning for Coherence }\end{array}$ & $\begin{array}{l}\text { My thinking got in the way of } \\
\text { things that were important to me }\end{array}$ & $\begin{array}{l}\text { I used my thinking in ways that } \\
\text { helped me live better }\end{array}$ \\
\hline Selection of Attention / & I struggled to connect with the & I paid attention to important things \\
\hline
\end{tabular}




\begin{tabular}{|l|l|l|}
\hline Yearning to be Oriented & moments in my day-to-day life & in my daily life; \\
\hline $\begin{array}{l}\text { Selection of Social } \\
\text { Connection / Need for } \\
\text { Connection }\end{array}$ & $\begin{array}{l}\text { I did things that hurt my } \\
\text { connection with people who are } \\
\text { important to me }\end{array}$ & $\begin{array}{l}\text { I did things to connect with people } \\
\text { who are important to me }\end{array}$ \\
\hline $\begin{array}{l}\text { Selection of Motivation / } \\
\text { Need for Autonomy }\end{array}$ & $\begin{array}{l}\text { I did things only because I was } \\
\text { complying with what others } \\
\text { wanted me to do }\end{array}$ & $\begin{array}{l}\text { I chose to do things that were } \\
\text { personally important to me }\end{array}$ \\
\hline $\begin{array}{l}\text { Selection of Overt } \\
\text { Cehavior / Need for }\end{array}$ & $\begin{array}{l}\text { I did not find a meaningful way to } \\
\text { challenge myself }\end{array}$ & $\begin{array}{l}\text { I found personally important ways } \\
\text { to challenge myself }\end{array}$ \\
\hline $\begin{array}{l}\text { Selection of Physical } \\
\text { Health Behaviors }\end{array}$ & $\begin{array}{l}\text { I acted in ways that hurt my } \\
\text { physical health }\end{array}$ & $\begin{array}{l}\text { I acted in ways that helped my } \\
\text { physical health }\end{array}$ \\
\hline Retention & $\begin{array}{l}\text { I struggled to keep doing } \\
\text { something that was good for me }\end{array}$ & $\begin{array}{l}\text { I stuck to strategies that seemed } \\
\text { to have worked }\end{array}$ \\
\hline
\end{tabular}

Note: As will be discussed below, three additional items were tested and ultimately removed yielding these 18 items. The items removed were a negative variation item: I changed my environment, to improve my life (examples: removing temptation; reducing distractions; surrounding myself with positive influences); and two negative retention items: I stuck to what I cared about, even in the face of difficulties and I've used what l've learned in everyday life. See text.

\section{Criterion-variables}

Clinically relevant outcomes. We used the five STOP-D items to measure sadness, anxiety, stress, anger, and lack of social support (Young et al., 2007, 2015). People rated the extent they felt each state, during the last week, on a 100-point scale ranging from "Not at all" to "a great deal". We utilized the single item health measure (Ware \& Sherbourne, 1992) to assess health in the past week. Responses ranged from 1 (poor) to 5 (excellent). Finally, to assess vitality, we used three positive items from the vitality scale (Ryan \& Frederick, 1997), including "during the last week, I felt energized", "vital and alive", and "nearly always felt alert and awake".. Responses ranged from not at all true (0) to very true (100). This scale demonstrated strong internal consistency $(\alpha=.89)$ 
Need satisfaction. Because the approach we took to "selection" in given dimensional areas is close to the concepts tested in needs psychology (Ryan \& Deci, 2017), we selected two items with strong factor loadings from existing subscales of the need satisfaction and need frustration scale related to autonomy, competence, and connection (Chen et al., 2015). Participants rated the items on a 100-point slider scale from "Definitely False" to "Definitely True".

\section{Statistical procedure}

Our main statistical approach to evaluating the PBAT contrasts with a traditional psychometric approach, in which the researcher seeks to identify latent variables that influence responses on scale items based on inter-item consistency. This approach is not applicable to single items. Our main analyses instead utilized a machine learning "evolutionary" algorithm to test the competitive ability of individual PBAT items to relate to each of our outcome variables. Focusing on the individual item level allows identification of high performing single items for use in intensive repeated-measures designs.

The machine learning algorithm selected was the Boruta algorithm, which builds on the random forest classification approach (Kursa et al., 2010). First, it extends the data set by creating randomly shuffled copies of all features, or shadow features, which are uncorrelated with responses. The data set is extended by at least five shadow features. Second, it runs a random forest classifier on the extended data set and gathers $Z$ scores, or an index of how much information is lost if that item is not included in prediction. Third, it finds the maximum $Z$ score among shadow attributes (the "MZSA"), and then assigns a hit to every item that scores better than MZSA. Fourth, it classifies every attribute or item that has importance significantly lower than the MSZA as "unimportant", and the attributes that have importance 
significantly higher than the MZSA as "important." Finally, it repeats this entire procedure multiple times to get statistically robust results. Over iterations the algorithm estimates the importance of each item via the mean decrease in accuracy of prediction if the item is not in the model.

The core building block for a random forest analysis is a decision tree, which is like an evolutionary process. To build a decision tree, the algorithm starts by randomly using one of the 21 PBAT items or "features" to predict an outcome. If that item predicts significant variance, it is considered a useful feature and it is selected. An additional feature (item) is then selected randomly and is retained if it predicts additional outcome variance given the selected feature and the best (i.e., the luckiest) shadow feature. The algorithm keeps adding features in this way, as long as the new feature adds significant value to prediction as defined above. When features no longer improve fit, the algorithm stops.

Because any one single decision tree may be inadequate to judge fitness, a full random forest analysis generates many different trees, each one considering only a random subset of features (i.e., items) and only having access to a random set of the training points. This process of inducing variation before selection and retention leads to more robust predictions, just as would happen in any evolutionary process. Each individual tree provides only an imperfect understanding of what items are likely to be best and retained but in the random forest the many decision trees are then combined into a single model.

Returning to the Boruta algorithm, we used the 100-default number of maximum runs and a confidence level/pvalue of .01 . At the end of 100 runs, attributes that were still tentative were confirmed or rejected by comparing the median Z score of the attributes with the median Z score of the best shadow 
attribute. Features were retained that were most consistently predictive across all iterations. The Boruta multiple adjustment parameter was set to true, which forces the algorithm to use the Bonferroni method to adjust for multiple comparisons.

\section{Results}

\section{Descriptives}

We present the means and standard deviations of the PBAT Table 2. Concerning positive behavior, participants felt least successful at finding meaningful challenges and most successful at paying attention to important things in daily life and choosing to do personally important things. Concerning negative behaviors, participants felt that problems with unhelpful thinking were most common, whereas hurting social connection was least common. There were also sex differences, with males more likely than females to report not experiencing a range of emotions appropriate to the moment, not paying attention to important things in daily life, complying with others, hurting their health and social connections, and not using what they learned in everyday life.

In contrast to sex differences on the PBAT, there were few sex differences in outcomes or need satisfaction measures. Males and females were not significantly different in sadness, anger, anxiety, stress, lack of support, or any form of need satisfaction, all $t s<1.96$, all $p s>.05$. Males were significantly more likely than females to report feeling more vital $\left(M_{\text {male }}=60.5, S D=21.4 ;\right.$ Mfemale $=56.1, S D=$ 22.9) and healthy $\left(\mathrm{M}_{\text {male }}=3.1, \mathrm{SD}=1.1 ;\right.$ Mfemale $\left.=2.9, \mathrm{SD}=.98\right), t s>2, p s<.05$.

Taken together, these results suggest that males report feeling better than females, despite reporting less positive behavior than females. Indeed, males are 
more likely than females to report engaging in behavior that hurts their health but are more likely to report feeling healthy.

Table 2: Means, standard deviations, and sex differences for PBAT items.

\begin{tabular}{|c|c|c|c|c|c|}
\hline \multirow[b]{2}{*}{ PBAT item } & \multicolumn{2}{|c|}{ Female } & \multicolumn{2}{|c|}{ Male } & \multirow[t]{2}{*}{$t_{\text {diff }}$} \\
\hline & M & SD & $\mathbf{M}$ & SD & \\
\hline & \multicolumn{4}{|c|}{ Positive Selection behavior } & \\
\hline Chose to do personally important things & 73.54 & 20.3 & 71.17 & 20.0 & 1.4 \\
\hline Helped My Health & 64.28 & 22.9 & 65.21 & 21.7 & -.5 \\
\hline Paid attention to important things in daily life & 74.53 & 18.1 & 71.44 & 19.5 & $2.0^{*}$ \\
\hline Connected with important people & 67.7 & 22.4 & 66.0 & 22.5 & .92 \\
\hline Experience range emotions approp. to moment & 68.87 & 20.4 & 62.88 & 23.1 & $3.3^{* * *}$ \\
\hline Found ways to challenge self & 63.3 & 21.9 & 63.62 & 22.4 & -.17 \\
\hline \multirow[t]{2}{*}{ Used thinking to live better } & 64.91 & 22.2 & 65.01 & 21.9 & -.05 \\
\hline & \multicolumn{4}{|c|}{ Negative Selection Behavior } & \\
\hline Did things only to comply to others & 48.11 & 27.7 & 54.39 & 27.9 & $-2.7 * *$ \\
\hline Hurt my health & 40.63 & 31.1 & 47.1 & 29.2 & $-2.6 * *$ \\
\hline Struggled to connect with moments of day & 48.78 & 27.6 & 52.96 & 27.0 & -1.9 \\
\hline Hurt social connections & 37.08 & 30.4 & 47.01 & 29.6 & $-4.0 * *$ \\
\hline Found no appropriate outlet for feelings & 45.29 & 28.3 & 50.01 & 28.2 & $-2.0^{*}$ \\
\hline Found no meaningful challenge & 48.09 & 28.5 & 52.58 & 27.5 & -1.9 \\
\hline \multirow[t]{2}{*}{ My thinking got in the way of important things } & 55.16 & 26.1 & 55.76 & 26.6 & -.27 \\
\hline & \multicolumn{4}{|c|}{ Variation } & \\
\hline Stuck \& unable to change ineffective behavior & 49.31 & 29.4 & 50.36 & 29.2 & -.44 \\
\hline Able to change behavior, when changing helped & 62.98 & 20.9 & 63.32 & 22.2 & -.19 \\
\hline \multirow[t]{2}{*}{ Changed my environment to improve life } & 63.05 & 22.6 & 60.48 & 24.8 & 1.32 \\
\hline & \multicolumn{4}{|c|}{ Retention } & \\
\hline Struggled to keep doing what was important & 53.28 & 27.6 & 55.94 & 27.4 & -1.2 \\
\hline Stuck to Strategies that worked & 62.93 & 22.9 & 64.55 & 21.3 & -.89 \\
\hline Used what i learned in everyday life & 72.23 & 18.5 & 68.81 & 21.0 & $2.1^{*}$ \\
\hline Stuck to what cared about, even in difficulties & 69.26 & 20.6 & 68.93 & 20.4 & .20 \\
\hline
\end{tabular}

Note: ${ }^{*} p<.05,{ }^{* *} p<.01,{ }^{* * *} p<>001$; Scale ranges from 0 (strongly disagree) to 100 (strongly agree). 


\section{Structural validity}

Hypothesis 1 suggested that positive and negative variation, selection, and retention behaviors would be distinctive and not mere opposite sides of the same continuum. Tables 3 and 4 support this hypothesis. All such seven positive items correlated significantly with the other positive items (mean $=+.38$; range $=+.28$ to +.58 ) and generally moderately with one small and one large correlation among the 21 calculated, using typical cut-offs of .3 and .5 for those categories. Similarly, all such seven negative items correlated significantly with each other $($ mean $=+.49$; range $=$ +.38 to +.63 ), also generally in the moderate range. Positive and negative items showed smaller and inconsistent relationships (mean $=-.05$; range $=+.28$ to -.18 ) Only 18 of the 49 relationships were statistically significant (range $=-.08$ to -.18 ) while 31 were not (range $=+.06$ to -.07 ) and all significant relationships were small. This suggests that people are engaging in both positive and negative behavior during the week. It is also worth noting that the correlations within positive and negative items do not suggest item redundancy. The strongest link $(r=.63)$ was between no outlet for feelings and struggled to connect with the moments in day-to-day life. 
Table 3: Link between positive and negative behavior

\begin{tabular}{|c|c|c|c|c|c|c|c|c|c|c|c|c|c|}
\hline & 1 & 2 & 3 & 4 & 5 & 6 & 7 & 8 & 9 & 10 & 11 & 12 & 13 \\
\hline 1. Personallmpor & - & & & & & & & & & & & & \\
\hline 2. HelpHealth & $0.32^{\star \star *}$ & - & & & & & & & & & & & \\
\hline 3. PaidAttTolmportant & $0.47^{* \star *}$ & $0.33^{\star \star *}$ & - & & & & & & & & & & \\
\hline 4. ConnectToPeople & $0.37^{* * *}$ & $0.35^{\star * *}$ & $0.39^{\star \star *}$ & - & & & & & & & & & \\
\hline 5. ExperienceRangeEmotions & $0.38^{\star \star *}$ & $0.28^{* * *}$ & $0.33^{\star \star *}$ & $0.39^{\star \star \star}$ & - & & & & & & & & \\
\hline 6. ImportantChallenge & $0.33^{* * *}$ & $0.45^{\star \star \star}$ & $0.37^{* * *}$ & $0.40^{\star \star *}$ & $0.30^{* \star *}$ & - & & & & & & & \\
\hline 7. ThinkingHelpedLife & $0.38^{* * *}$ & $0.45^{* * *}$ & $0.32^{* * *}$ & $0.50^{* * *}$ & $0.32^{* * *}$ & $0.58^{* * *}$ & - & & & & & & \\
\hline 8. Complying & -0.03 & 0.02 & -0.03 & -0.04 & 0.06 & 0 & -0.05 & - & & & & & \\
\hline 9. HurtHealth & -0.07 & $-0.08^{*}$ & $-0.18^{* * *}$ & $-0.10^{*}$ & 0.05 & -0.02 & -0.05 & $0.38^{\star \star *}$ & - & & & & \\
\hline 10. StruggleConnectMoments & $-0.08^{*}$ & -0.04 & $-0.10^{*}$ & $-0.09^{*}$ & -0.06 & -0.04 & $-0.08^{*}$ & $0.47^{\star \star *}$ & $0.44^{\star \star *}$ & - & & & \\
\hline 11. HurtConnect & $-0.14^{* * *}$ & 0 & $-0.12^{* *}$ & $-0.16^{* * *}$ & $-0.11^{* *}$ & 0.05 & -0.06 & $0.47^{\star \star *}$ & $0.51^{* * *}$ & $0.52^{* * *}$ & - & & \\
\hline 12. NoOutletForFeelings & -0.07 & -0.05 & $-0.12^{* *}$ & $-0.15^{\star * *}$ & -0.03 & 0 & -0.07 & $0.48^{* * *}$ & $0.51^{* * *}$ & $0.63^{* * *}$ & $0.58^{* * *}$ & - & \\
\hline 13. NoMeaningfulChallenge & -0.04 & -0.01 & $-0.15^{\star * *}$ & $-0.15^{\star * *}$ & 0.03 & $-0.10^{*}$ & $-0.10^{*}$ & $0.45^{\star \star *}$ & $0.46^{* * *}$ & $0.55^{\star \star *}$ & $0.48^{* \star *}$ & $0.58^{* * *}$ & - \\
\hline 14. ThinkingGotInWay & 0.04 & -0.02 & -0.07 & $-0.11^{* *}$ & 0.05 & 0.05 & -0.01 & $0.45^{\star * *}$ & $0.45^{\star \star *}$ & $0.47^{* * *}$ & $0.45^{\star * *}$ & $0.53^{* * *}$ & $0.46^{* * *}$ \\
\hline
\end{tabular}

Note: shaded area is relationship between positive and negative behavior 
Table 4: Relationship between variation and retention items

\begin{tabular}{llllllll}
\hline & & $\mathbf{1}$ & $\mathbf{2}$ & $\mathbf{3}$ & $\mathbf{4}$ & $\mathbf{5}$ & $\mathbf{6}$ \\
\hline 1. StruggledToKeepDoing & - & & & & & \\
2. StuckUnableChange & $0.53^{* * *}$ & - & & & & \\
3. StuckToStrategies & -0.02 & -0.06 & - & & & \\
4. StuckToWhatCared & 0.05 & -0.06 & $0.31^{* * *}$ & - & \\
5. AbleToChangeBehavior & $0.08^{*}$ & -0.02 & $0.42^{* * *}$ & $0.35^{* * *}$ & - \\
6. UsedWhatLearned & 0.01 & $-0.11^{* *}$ & $0.34^{* * *}$ & $0.46^{* * *}$ & $0.46^{* * *}-$ \\
7. ChangedEnvironment & 0.08 & 0.06 & $0.39^{* * *}$ & $0.23^{* * *}$ & $0.41^{* * *}$ & $0.36^{* * *}$ \\
\hline
\end{tabular}

\section{Criterion validity}

Hypothesis 2 suggested that PBAT 21-items should link to the theoretically related measures of need satisfaction. In other words, engaging in effective variation, selection, and retention should help satisfy the need for connection, competence, and autonomy. Consistent with this hypothesis, as is shown in Table 5, positive behaviors were moderately linked to all three forms of need satisfaction (mean $=$ +.38 ; range $=+.24$ to +.52 ), but not need frustration (mean $=-.06$; range $=+.17$ to .19). Conversely, negative behaviors were moderately to strongly linked to all three forms of need frustration ( mean $=+.48$; range $=+.40$ to +.62 ), but not need satisfaction $($ mean $=-.13$; range $=+.01$ to -.25$)$. 
Table 5: Link of PBAT items to satisfaction and frustration of the need for autonomy competence, and connection.

\begin{tabular}{|c|c|c|c|c|c|c|}
\hline & 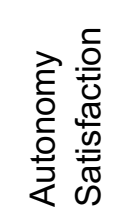 & 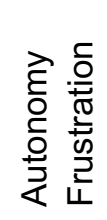 & 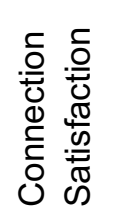 & 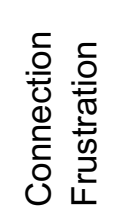 & 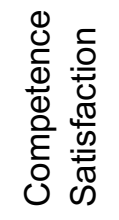 & 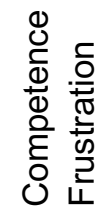 \\
\hline \multicolumn{7}{|l|}{ Positive selection } \\
\hline Personallmpor & $0.44^{\star * *}$ & -0.07 & $0.36^{* * *}$ & $-0.11^{\star *}$ & $0.34^{\star \star *}$ & $-0.12^{* *}$ \\
\hline HelpHealth & $0.40^{* * *}$ & -0.06 & $0.36^{* * *}$ & -0.03 & $0.40^{* * *}$ & $-0.12^{* *}$ \\
\hline PaidAttTolmportant & $0.37^{\star \star *}$ & $-0.10^{*}$ & $0.42^{* * *}$ & $-0.10^{*}$ & $0.36^{\star * *}$ & $-0.18^{* * \star}$ \\
\hline ConnectToPeople & $0.33^{\star * \star}$ & $-0.10^{*}$ & $0.42^{* \star *}$ & $-0.19^{* * *}$ & $0.42^{\star * *}$ & $-0.19^{* * *}$ \\
\hline ExperienceRangeEmotions & $0.29^{\star \star \star}$ & -0.01 & $0.34^{* * *}$ & -0.05 & $0.27^{\star * *}$ & $-0.10^{*}$ \\
\hline ImportantChallenge & $0.52^{\star \star *}$ & 0 & $0.39^{* * *}$ & 0.04 & $0.47^{\star * *}$ & $-0.13^{\star *}$ \\
\hline ThinkingHelpedLife & $0.44^{\star \star *}$ & -0.08 & $0.45^{\star \star \star}$ & $-0.08^{*}$ & $0.51^{* * *}$ & $-0.17^{* \star *}$ \\
\hline Complying & -0.06 & $0.48^{\star * *}$ & $-0.10^{*}$ & $0.42^{* * *}$ & $-0.11^{* *}$ & $0.41^{* * *}$ \\
\hline \multicolumn{7}{|l|}{ Negative selection } \\
\hline HurtHealth & -0.06 & $0.42^{* * *}$ & $-0.12^{\star *}$ & $0.40^{* * *}$ & $-0.14^{* * *}$ & $0.41^{* * *}$ \\
\hline StruggleConnectMoments & -0.07 & $0.53^{\star \star *}$ & $-0.21^{* * *}$ & $0.52^{* * *}$ & $-0.20^{* * *}$ & $0.54^{* * *}$ \\
\hline HurtConnect & -0.04 & $0.45^{\star \star *}$ & $-0.18^{* * *}$ & $0.54^{* * *}$ & $-0.14^{* * *}$ & $0.42^{* * *}$ \\
\hline NoOutletForFeelings & -0.05 & $0.51^{* * *}$ & $-0.21^{* \star *}$ & $0.51^{* \star *}$ & $-0.21^{\text {*** }}$ & $0.55^{\star \star *}$ \\
\hline NoMeaningfulChallenge & -0.06 & $0.40^{* * *}$ & $-0.17^{\star \star *}$ & $0.46^{\star \star \star}$ & $-0.18^{* * *}$ & $0.53^{\star * *}$ \\
\hline ThinkingGotlnWay & 0 & $0.42^{\star * *}$ & $-0.15^{\star \star *}$ & $0.50^{* \star *}$ & $-0.20^{* * *}$ & $0.50^{\star * *}$ \\
\hline \multicolumn{7}{|l|}{ Variation } \\
\hline AbleToChangeBehavior & $0.40^{\star * *}$ & 0 & $0.33^{* * *}$ & 0.07 & $0.42^{* * *}$ & $-0.09^{*}$ \\
\hline StuckUnableChange & $-0.11^{\star *}$ & $0.51^{* \star *}$ & $-0.23^{\star \star *}$ & $0.54^{\star \star \star}$ & $-0.25^{\star \star *}$ & $0.62^{* * *}$ \\
\hline ChangedEnvironment & $0.34^{* \star *}$ & $0.10^{*}$ & $0.24^{* * *}$ & $0.17^{* \star *}$ & $0.30^{\star \star *}$ & 0.02 \\
\hline \multicolumn{7}{|l|}{ Retention } \\
\hline StruggledToKeepDoing & 0.01 & $0.42^{\star * *}$ & $-0.15^{\star \star \star}$ & $0.44^{\star \star *}$ & $-0.16^{* * *}$ & $0.46^{\star * *}$ \\
\hline StuckToStrategies & $0.35^{\star \star *}$ & -0.02 & $0.34^{* * *}$ & -0.04 & $0.40^{* \star *}$ & $-0.12^{* *}$ \\
\hline StuckToWhatCared & $0.36^{* * *}$ & 0.01 & $0.26^{* * *}$ & -0.01 & $0.38^{* * *}$ & -0.07 \\
\hline UsedWhatLearned & $0.41^{* \star *}$ & -0.08 & $0.33^{* * *}$ & -0.08 & $0.44^{* * *}$ & $-0.16^{* * *}$ \\
\hline
\end{tabular}


Finally, Hypothesis 3 suggested that the PBAT items should link to clinically relevant outcomes. Table 6 supports this prediction. Positive items predicted health and vitality best (mean $=+.25$; range $=+.05$ to +.43 ) as compared to negative items (mean $=-.12$; range $=.00$ to -.25$)$, whereas negative items predicted sadness, anxiety, stress, anxiety, and lack of support (mean $=+.42$; range $=+.31$ to +.52$)$ more so than positive items (mean $=-.07$; range $=+.12$ to -.20 ). None of the correlations were so high as to suggest the PBAT was redundant with outcome measures.

Table 6: Link between PBAT and clinically relevant outcomes

\begin{tabular}{|c|c|c|c|c|c|c|c|}
\hline & Sad & Anxious & Stressed & Angry & NoSupp & Health & Vital \\
\hline \multicolumn{8}{|l|}{ Positive Selection } \\
\hline Personallmpor & $-0.17^{\star * *}$ & $-0.09^{*}$ & $-0.09^{*}$ & $-0.17^{\star * *}$ & $-0.11^{* *}$ & $0.18^{* * *}$ & $0.30^{* * *}$ \\
\hline HelpHealth & $-0.15^{\star \star *}$ & $-0.13^{* *}$ & $-0.11^{\star *}$ & -0.04 & -0.04 & $0.29^{\star \star \star}$ & $0.42^{\star \star \star}$ \\
\hline PaidAttTolmportant & $-0.14^{\star \star \star}$ & $-0.08^{*}$ & $-0.08^{*}$ & $-0.16^{\star \star \star}$ & $-0.11^{\star *}$ & $0.19^{\star \star \star}$ & $0.33^{\star \star \star}$ \\
\hline ConnectToPeople & $-0.18^{\star \star \star}$ & $-0.14^{\star \star *}$ & $-0.12^{* *}$ & $-0.20^{\star \star *}$ & $-0.13^{* *}$ & $0.14^{* * *}$ & $0.29^{* * *}$ \\
\hline ExperienceRangeEmotions & -0.07 & 0.03 & 0 & -0.02 & 0 & 0.05 & $0.20^{\star \star *}$ \\
\hline ImportantChallenge & $-0.10^{*}$ & $-0.12^{\star *}$ & -0.07 & $-0.09^{*}$ & 0.02 & $0.19^{\star \star \star}$ & $0.43^{* * *}$ \\
\hline ThinkingHelpedLife & $-0.17^{\star \star \star}$ & $-0.12^{* *}$ & $-0.12^{* *}$ & $-0.16^{* \star *}$ & -0.07 & $0.20^{* * *}$ & $0.43^{* * *}$ \\
\hline \multicolumn{8}{|l|}{ Negative Selection } \\
\hline Complying & $0.37^{* * *}$ & $0.35^{\star * *}$ & $0.37^{* * *}$ & $0.39^{* * *}$ & $0.37^{\star * *}$ & $-0.13^{* *}$ & $-0.10^{*}$ \\
\hline HurtHealth & $0.36^{* * *}$ & $0.35^{* * *}$ & $0.31^{* * *}$ & $0.38^{* * *}$ & $0.38^{* * *}$ & $-0.16^{* * *}$ & $-0.12^{\star *}$ \\
\hline StruggleToConnectMoments & $0.52^{* \star \star}$ & $0.51^{\star * \star}$ & $0.47^{\star \star \star}$ & $0.48^{* * *}$ & $0.48^{* * *}$ & $-0.15^{\star \star \star}$ & $-0.12^{\star *}$ \\
\hline HurtConnect & $0.36^{* \star *}$ & $0.35^{\star \star \star}$ & $0.37^{* \star \star}$ & $0.44^{* * *}$ & $0.45^{\star \star *}$ & -0.03 & 0 \\
\hline NoOutletForFeelings & $0.52^{* * *}$ & $0.50^{* * *}$ & $0.44^{* * *}$ & $0.48^{* * *}$ & $0.51^{* * *}$ & $-0.16^{\star \star *}$ & $-0.13^{* *}$ \\
\hline NoMeaningfulChallenge & $0.42^{\star * \star}$ & $0.36^{\star * *}$ & $0.34^{* \star *}$ & $0.38^{* \star *}$ & $0.41^{* \star *}$ & $-0.16^{* \star *}$ & $-0.11^{\star}$ \\
\hline ThinkingGotInWay & $0.43^{* * *}$ & $0.42^{* * *}$ & $0.44^{* * *}$ & $0.39^{* * *}$ & $0.45^{\star * *}$ & $-0.09^{*}$ & $-0.09^{*}$ \\
\hline \multicolumn{8}{|l|}{ Variation } \\
\hline AbleToChangeBehavior & $-0.12^{\star \star}$ & -0.06 & -0.07 & -0.06 & 0.03 & $0.24^{\star \star \star}$ & $0.40^{* \star *}$ \\
\hline ChangedEnvironment & 0.02 & 0.02 & 0.03 & 0.02 & $0.12^{\star \star}$ & $0.16^{\star * *}$ & $0.29^{* \star *}$ \\
\hline
\end{tabular}


StuckUnableChange $\quad 0.51^{* * *} \quad 0.47^{* * *} \quad 0.48^{* * *} \quad 0.47^{* * *} \quad 0.51^{* * *} \quad-0.25^{* * *} \quad-0.19^{\star * *}$

Retention

StruggledToKeepDoing $\quad 0.39^{\star \star *} \quad 0.40^{\star \star *} \quad 0.39^{\star \star *} \quad 0.37^{\star \star *} \quad 0.43^{\star \star *} \quad-0.12^{\star *} \quad-0.10^{*}$

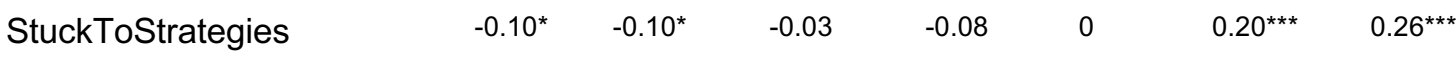

$\begin{array}{llllllll}\text { StuckToWhatCared } & -0.08 & 0.04 & -0.01 & -0.04 & -0.04 & 0.07 & 0.17^{* * *}\end{array}$

$\begin{array}{llllllll}\text { UsedWhatLearned } & -0.14^{* * *} & -0.03 & -0.07 & -0.16^{* * *} & -0.07 & 0.19^{* \star *} & 0.32^{* * *}\end{array}$

Our final analysis utilized machine learning to identify the most important predictors of each clinically relevant outcome (see statistical procedure section). The analyses are fully reported in supplementary materials. Table 7 shows the item rank relative to the specified outcome $(1=$ top ranked $)$.

All PBAT items were significant predictors of at least three clinically relevant outcomes. Able to change behavior was unranked three times but still was a top 5 predictor of vitality and health. In general, the negative items tended to link to the negative outcomes, and positive items linked to positive outcomes. The top predictor of all negative states was struggled to connect to day-to-day moments of life; the top predictor of health and vitality was I acted in ways that helped my physical health.

Table 7: Ranked relative importance of PBAT items for six clinically relevant outcomes 


\begin{tabular}{|c|c|c|c|c|c|c|c|c|c|}
\hline & & & Sad & Anxious & Stress & Anger & No Support & Vital & Health \\
\hline \multirow{7}{*}{ 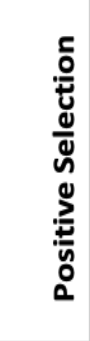 } & \multicolumn{2}{|c|}{ Personallmpor } & 11 & Unranked & Unranked & 14 & 15 & 10 & Unranked \\
\hline & HelpHealth & & 13 & 10 & 10 & Unranked & 17 & 1 & 1 \\
\hline & \multicolumn{2}{|c|}{ PaidAttTolmportant } & Unranked & 13 & 15 & 12 & 13 & 6 & Unranked \\
\hline & \multicolumn{2}{|c|}{ ConnectToPeople } & 10 & 16 & 19 & 10 & 10 & 18 & Unranked \\
\hline & \multicolumn{2}{|c|}{ ExperienceRangeEmotions } & 18 & 15 & 13 & Unranked & 18 & 21 & Unranked \\
\hline & \multicolumn{2}{|c|}{ ImportantChallenge } & 16 & 11 & 20 & 15 & 14 & 2 & 11 \\
\hline & \multicolumn{2}{|c|}{ ThinkingHelpedLife } & 14 & 17 & 12 & 13 & 12 & 3 & 8 \\
\hline \multirow{7}{*}{ 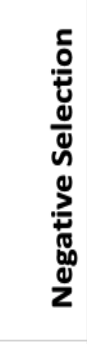 } & Complying & & 5 & 9 & 7 & 7 & 7 & 14 & 13 \\
\hline & HurtHealth & & 8 & 6 & 9 & 5 & 9 & 20 & 6 \\
\hline & \multicolumn{2}{|c|}{ StruggleToConnectMomen } & 1 & 1 & 1 & 1 & 3 & 7 & 12 \\
\hline & \multicolumn{2}{|c|}{ HurtConnect } & 9 & 8 & 6 & 4 & 4 & 19 & Unranked \\
\hline & \multicolumn{2}{|c|}{ NoOutletForFeelings } & 2 & 2 & 4 & 3 & 2 & 16 & 15 \\
\hline & \multicolumn{2}{|c|}{ NoMeaningfulChallenge } & 6 & 7 & 8 & 8 & 8 & 8 & 5 \\
\hline & \multicolumn{2}{|c|}{ ThinkingGotInWay } & 4 & 4 & 3 & 6 & 5 & 9 & 10 \\
\hline \multirow{2}{*}{$\stackrel{\oplus 0}{z} \stackrel{\varphi}{>}$} & \multicolumn{2}{|c|}{ StruggledToKeepDoing } & 7 & 5 & 5 & 9 & 6 & 12 & 9 \\
\hline & \multicolumn{2}{|c|}{ StuckUnableChange } & 3 & 3 & 2 & 2 & 1 & 13 & 2 \\
\hline \multirow{2}{*}{$\stackrel{\wp}{\circ} \stackrel{\Upsilon}{>}$} & \multicolumn{2}{|c|}{ StuckToStrategies } & 15 & 12 & 14 & Unranked & 19 & 11 & 4 \\
\hline & \multicolumn{2}{|c|}{ AbleToChangeBehavior } & Unranked & 18 & 11 & Unranked & Unranked & 4 & 3 \\
\hline \multirow{3}{*}{ 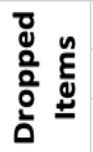 } & \multicolumn{2}{|c|}{ StuckToWhatCared } & 17 & 14 & 17 & 17 & 16 & 17 & Unranked \\
\hline & \multicolumn{2}{|c|}{ UsedWhatLearned } & 12 & Unranked & 16 & 11 & 11 & 15 & 14 \\
\hline & \multicolumn{2}{|c|}{ ChangedEnvironment } & Unranked & Unranked & 18 & 16 & Unranked & 5 & 7 \\
\hline
\end{tabular}

Note: $\mathrm{V} / \mathrm{R}=$ Variation and retention items

Note: Unranked = Feature was a non-significant predictor (see supplemental section for full results of machine learning analyses).

Some PBAT items were top ten predictors of all negative outcomes, including compliance, hurting connection, hurting health, having no meaningful challenge, having no outlet for feelings, struggling to keep doing something important, struggling to connect to moments, stuck and unable to change, and thinking getting in the way. Concerning positive outcomes, positive variation (able to change behavior, changed environment) most clearly linked to vitality and health, and did not tend to link to negative outcomes. Vitality was most closely linked to Helping health, having a meaningful challenge, and thinking helped. Health was most strongly linked to helping health, ability to change behavior, and stuck and unable to change. 
Based on these ratings, we created a recommended measure that includes one positive and negative item for each of the key elements of the Extended Evolutionary Meta model (see Table 1). Items excluded from the final recommended list included two retention items that were not a top ten predictor of any outcome (I stuck to what I cared about, even in the face of difficulties, and I've used what I've learned in everyday life). In addition, changed environment was a slightly worse predictor than changed behavior, so the latter was preferred. However, changed environment was ranked in the top 5 for vitality and top 10 for health and thus readers may wish to use the item when those goals are key. Unlike a traditional psychometric evaluation, individual item choices like that have no impact on the other items, since the PBAT is an item collection, not a scale.

Figure 1 shows the mean importance score for each of the retained item after 100 iterations of the algorithm. If the overall importance score fell below significance as measured against the best performing shadow variable, no value is shown in the figure. Specific numerical values for both Table 7 and Figure 1 can be found in the supplementary materials.

Note that while there are 18 items, items were in essence evaluated individually albeit competitively, and thus researchers or practitioners should use these items as a tool drawer and should feel free to use fewer or more items, depending on the purpose. The overall item importance to specific outcomes (see Table 7) can be used to guide item selection, but so too can theoretical case conceptualization (Hofmann et al., 2021) or guidance by subsequent empirical idionomic analyses since these the data in this study are not longitudinal. Studies of that kind are already being done using the PBAT (Sanford, 2021). 


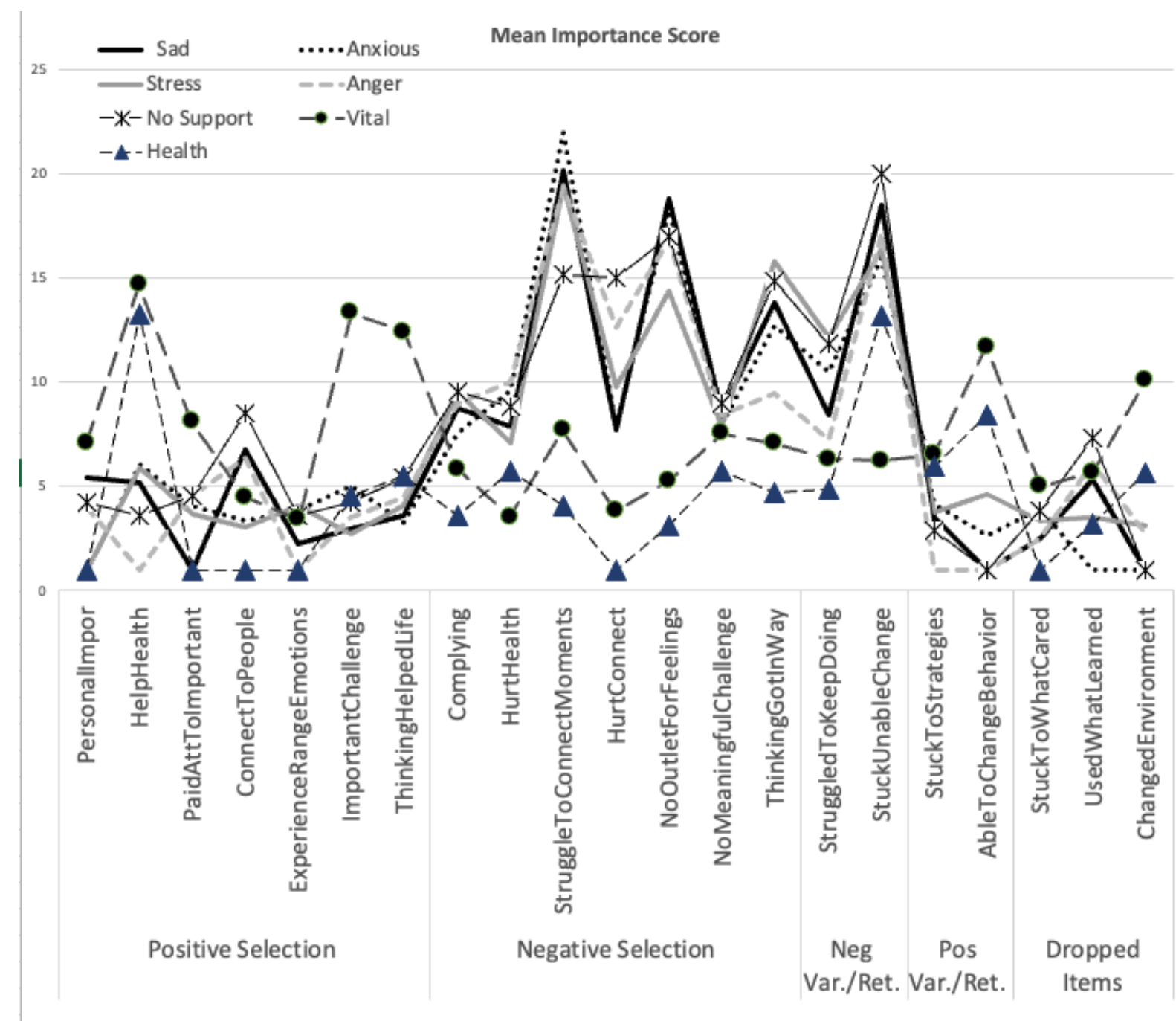

Note: Var./Ret. = variation and retention items

\section{Discussion}

The goal of the PBAT is to give researchers and practitioners a guide to a minimal, viable set of process-based items they can use to model and predict important processes of change that may interact to foster clinical outcomes. The results suggest that the PBAT may provide a useful beginning pool of items for research involving intensive, repeated measures of processes of change in individual clients.

Processes of change are defined as theory-based, dynamic, progressive, contextually bound, modifiable, and multilevel sequences linked to important 
outcomes (Hayes, Hofmann, \& Ciarrochi, 2020a). In the development of the PBAT item set, the EEMM and evolutionary theory was used most heavily to help generate items and to make predictions about item performance.

Items were designed to be contextually bound and focused on modifiable sequences by specifying actions focused on dimensions or level of responding in particular contexts. Items were designed to be multi-level in that sociocultural and biophysiological features were included, not just psychological items.

One area that was more difficult to address is that of "selection" since any action that leads to valued ends could be selected on that basis. In that area we relied on self-determination theory (Ryan \& Deci, 2017), with its emphasis on the desire to connect and belong, to be competent, and to be able to choose what is most meaningful, relatively free of coercion and constraint. This framework has been extensively evaluated, and actions that promote these ends have been shown to promote well-being and positive life outcomes (Donald et al. 2020; $\mathrm{Ng}$ et al. 2012; Vasconcellos et al. 2020; Van den Broeck et al. 2016; Tang, Wang, and Guerrien 2020). These also line up with the EEMM areas of sense of self, overt behavior, and motivation well, but it leaves unclear what might be of proximal importance in the areas of affect, attention, and cognition. In this area we relied on psychological flexibility theory (Hayes, 2019), which suggests that people yearn for opportunities to feel, to be oriented, to find coherence and understanding in these three areas respectively.

We also found it difficult to construct items directly around sense of self, but by linking that area to a motivation to belong and connect, while still having a sense of autonomy and the ability to say what is of personal importance, it seems as though the social and cognitive areas could cover that dimension reasonably well. 
The EEMM is not meant to have processes of change be sorted into boxes in a grid. Often variation, selection, retention, and context sensitivity areas blend across several rows of the EEMM. That was one reason we added items in the areas of variation and retention, leaving to additional research the process of adding and subtracting items within the EEMM structure. The PBAT as it is a "proof of concept" designed to allow idionomic research in PBT to proceed.

In accord with theoretical expectations, positive and negative PBAT behaviors were found to be distinctive (Hypothesis 1) and linked in coherent ways to established measures of need satisfaction (Hypothesis 2). Furthermore, all items were selected based on their competitive ability to relate to common positive and negative clinical outcomes, which they all did (Hypothesis 3 ). The real proof of concept, however, will follow only as the PBAT is applied to idionomic research itself. One reason that is true is that there are features of processes of change that could not be tested in this study. Processes of change are dynamic, because they may involve feedback loops and non-linear relationships, and progressive, because they may need to be arranged in sequences to reach the treatment goal (or speaking in terms of maladaptation, they may occur in self-sustaining problematic sequences). These features can only be detected in longitudinal studies using high density temporal measurement. Creating an item pool for such use was a purpose of the present study but the utility of the PBAT for that purpose is only now being evaluated (Sanford, 2021).

The top identified predictors of outcomes correspond to processes that are typically emphasized in a wide variety of major therapy types, as should be expected given its catholic purposes. For example, most forms of cognitive behavioral therapy (Butler et al., 2006; Hofmann et al., 2012) focus on problematic cognition, and the 
two PBAT cognition items (thinking helped, thinking got in the way) were top predictors of positive and negative outcomes, respectively. Some forms of evidencebased therapy such as acceptance and commitment therapy (Hayes et al., 1999) or emotional-focused therapy (Greenberg, 2010) focus on restricted experience of emotions, and it was notable that an absence of appropriate ways to contact affect ( $I$ did not find an appropriate outlet for emotions) was a top predictor of negative outcomes. More behaviorally focused methods of intervention, such as behavioral activation (Dimidjian et al., 2006; Kanter et al., 2010) and problem-solving therapy (Eskin et al., 2008; Nezu \& Nezu, 2001) would be supported by findings that behavioral rigidity (stuck unable to change strategies) strongly predicted negative outcomes while behavioral flexibility (I was able to change my behavior) predicted positive outcomes. Consistent with interpersonal therapies (de Mello et al., 2005;Maitland, 2015; Tsai et al., 2009),the social process item, Hurt my connection with people that are important to me, was a top predictor of negative outcomes, especially of anger and lack of social support. Mindfulness or attentional training methods such as MBCT (Fjorback et al., 2011), DBT (Neacsiu et al., 2010), ACT (Hayes et al., 1999) or Meta-cognitive therapy (Wells, 2008; Wells \& Colbear, 2012) would be supported by the importance of the attention item, I struggled to connect to the moments of my day to day life. More bodily focused or wellness focused approaches (Dindo et al., 2017; Kini \& Ho, 2018) would find support in the link between acting in ways to help health and positive outcomes.

From a Process-Based Therapy perspective, however, it is important to notice that all these processes can be important in some situations, for some clients, with reference to some goals. It makes little sense to develop myriad forms of intervention defined by treatment topographies, specific techniques, or narrow populations if 
clients present with a much wider variety of challenges in biopsychosocial processes of change. Furthermore, absent a clear connection to processes of change it makes little sense to continue to develop treatment method after overlapping treatment method. We have argued previously (Hayes, Hofmann, \& Ciarrochi, 2020a) that one value of the EEMM is that it raises the theoretical bar on all forms of evidence-based therapy, challenging them to show that their approaches can apply in a comprehensive way to contextually sensitive variation and selective retention issues across all major dimensions and levels of human functioning. Once evidence-based therapy is reconceptualized as an intervention that modifies processes of change that are of known importance, it is an open question whether and when syndromally focused methods might add values to more comprehensive methods that can be modularized to target specific biopsychosocial processes based on client need as identified, for example, by the PBAT.

Whilst the PBAT has clear theoretical links to psychological needs and clinically relevant outcomes, its value lies in its ability to function as an item toolkit that is distinct from these constructs. If, for example, the PBAT was just another measure of psychological needs, there would be no need to prefer it to the currently established needs measure. PBAT items correlated only modestly with outcomes and needs, suggesting they are not redundant. Furthermore, the inclusion of the yearnings framework undergirding psychological flexibility (Hayes 2019) added useful items beyond the competence, connectedness, and autonomy focus of SDT. All selection behaviors linked to the yearnings framework predicted significant variance in clinically relevant outcomes, and all made significant contributions to need satisfaction. 
Variation and retention items were also important predictors of needs and outcomes. PBAT items focused on changing behavior or changing the environment were particularly good predictors of vitality. This finding could link to Fredrickson's broaden and build approach (Fredrickson, 2001; Fredrickson \& Joiner, 2018), which suggests that positive affect prompts people to be exploratory, playful, curious, and experimental. This behavioral variation is expected to result in the development of new social resources and skills. Future process research is needed to examine if positive affect drives positive variation in the PBAT, or positive variation drives positive affect, or both.

A specific and unexpected finding was that relative to females, males reported engaging in less positive behavior and more negative behavior but did not report worse well-being or lower need satisfaction. For example, males reported doing more to hurt their relationships, and yet reported experiencing the same relationship need satisfaction as females. Males reported doing more to hurt their health, and yet report feeling healthier than females. More research linked to objective outcomes will be needed to interpret these differences.

\section{Conclusions and future directions}

This study was meant as a beginning step toward developing a processbased assessment tool that allows clinicians and researchers the freedom to select individual items or sets of items for use in idionomic research and practice. Future research using idionomic methods such as GIMME (Gates \& Molenaar, 2012) will be needed to establish how the PBAT items interact over time in a dynamic and progressive way to predict changes in outcome, an essential feature of a process variable. Research will also be needed to examine if specific intervention kernels move specific PBAT-assessed processes. Those are precisely the empirical 
challenges of process-based therapy more generally. The PBAT does not provide a solution to these challenges -- only a beginning method for assessing whether they can be met. 


\section{Appendix}

To use the form, please enter your preferred time frame and context in the blank.

Examples might be, "During the last week", "During this day", "During the second half of this day," "During the last hour", and "While at work today". 


\section{PBAT}

Please mark on the line how much you agree with each statement. Base these responses on how you have been acting in the last week. Remember, there are no right or wrong answers.

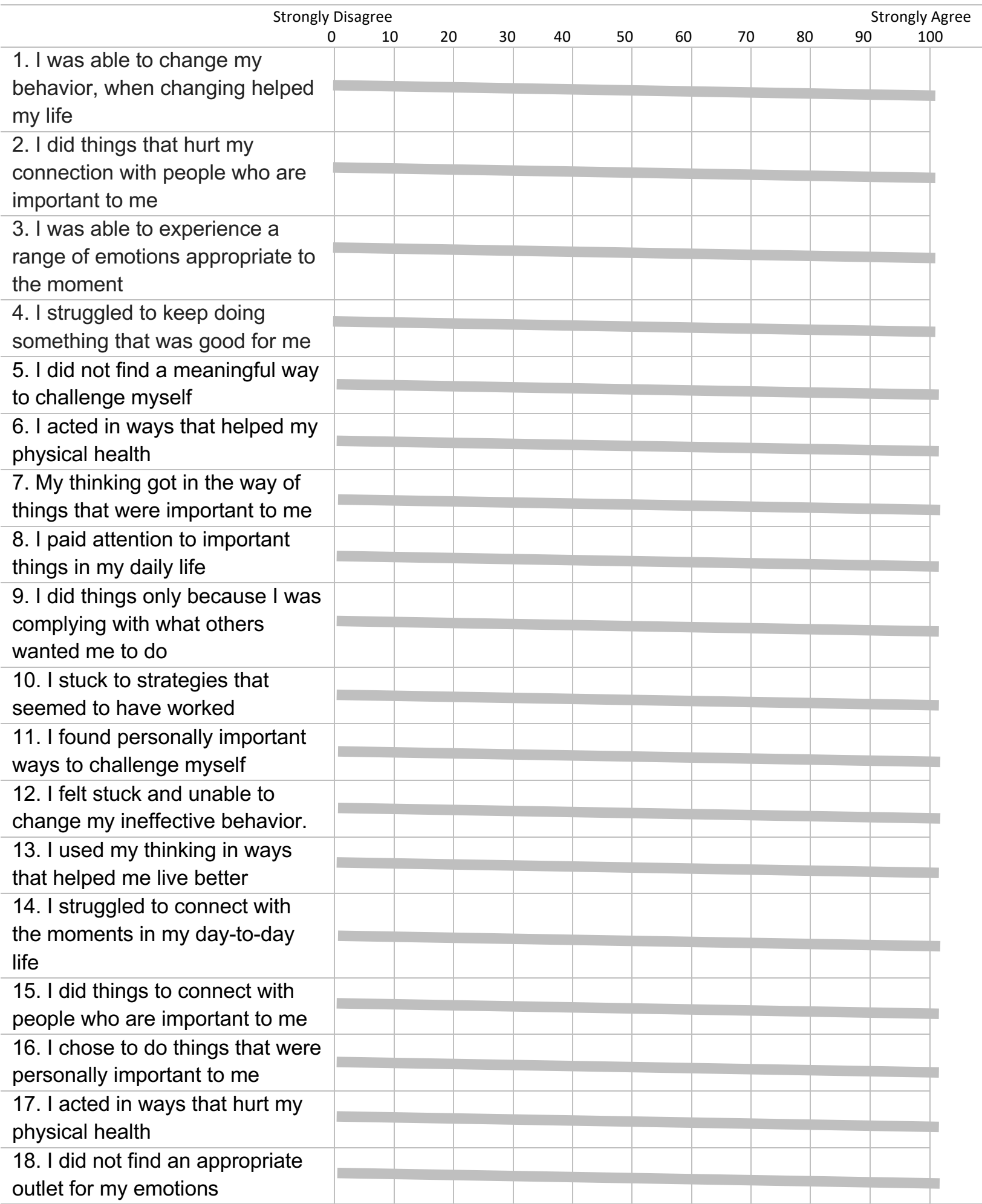




\section{References}

Ashley, S. (2015). Core concept: Ergodic theory plays a key role in multiple fields.

Proceedings of the National Academy of Sciences of the United States of America, 112(7), 1914.

Bartholomew, K. J., Ntoumanis, N., Ryan, R. M., Bosch, J. A. \& Thøgersen-Ntoumani, C. (2011). Self-determination theory and diminished functioning: the role of interpersonal control and psychological need thwarting. Personality \& Social Psychology Bulletin, 37(11), 1459-1473.

Birkhoff, G. D. (1931). Proof of the Ergodic Theorem. Proceedings of the National Academy of Sciences of the United States of America, 17(12), 656-660.

Borsboom, D., Cramer, A. \& Kalis, A. (2018). Brain disorders? Not really... Why network structures block reductionism in psychopathology research. The Behavioral and Brain Sciences, 42, 1-54.

Butler, A. C., Chapman, J. E., Forman, E. M. \& Beck, A. T. (2006). The empirical status of cognitive-behavioral therapy: a review of meta-analyses. Clinical Psychology Review, 26(1), 17-31.

Chen, B., Vansteenkiste, M., Beyers, W., Boone, L., Deci, E. L., Van der Kaap-Deeder, J., Duriez, B., Lens, W., Matos, L., Mouratidis, A., Ryan, R. M., Sheldon, K. M., Soenens, B., Van Petegem, S. \& Verstuyf, J. (2015). Basic psychological need satisfaction, need frustration, and need strength across four cultures. Motivation and Emotion, 39(2), 216236.

Cuijpers, P., Berking, M., Andersson, G., Quigley, L., Kleiboer, A. \& Dobson, K. S. (2013). A meta-analysis of cognitive-behavioural therapy for adult depression, alone and in comparison with other treatments. Canadian Journal of Psychiatry. Revue Canadienne de Psychiatrie, 58(7), 376-385.

de Mello, M. F., de Jesus Mari, J., Bacaltchuk, J., Verdeli, H. \& Neugebauer, R. (2005). A 
systematic review of research findings on the efficacy of interpersonal therapy for depressive disorders. European Archives of Psychiatry and Clinical Neuroscience, 255(2), 75-82.

Dimidjian, S., Hollon, S. D., Dobson, K. S., Schmaling, K. B., Kohlenberg, R. J., Addis, M. E., Gallop, R., Mcglinchey, J. B., Markley, D. K., Gollan, J. K., Atkins, D. C., Dunner, D. L. \& Jacobson, N. S. (2006). Randomized Trial of Behavioral Activation, Cognitive Therapy, and Antidepressant Medication in the Acute Treatment of Adults With Major Depression. Journal of Consulting and Clinical Psychology, 74(4), 658-670.

Dindo, L., Van Liew, J. R. \& Arch, J. J. (2017). Acceptance and Commitment Therapy: A Transdiagnostic Behavioral Intervention for Mental Health and Medical Conditions. Neurotherapeutics: The Journal of the American Society for Experimental NeuroTherapeutics, 14(3), 546-553.

Eskin, M., Ertekin, K. \& Demir, H. (2008). Efficacy of a Problem-Solving Therapy for Depression and Suicide Potential in Adolescents and Young Adults. Cognitive Therapy and Research, 32(2), 227-245.

Fisher, A. J., Medaglia, J. D. \& Jeronimus, B. F. (2018). Lack of group-to-individual generalizability is a threat to human subjects research. Proceedings of the National Academy of Sciences of the United States of America, 115(27), E6106-E6115.

Fisher, A. J., Reeves, J. W., Lawyer, G., Medaglia, J. D. \& Rubel, J. A. (2017). Exploring the idiographic dynamics of mood and anxiety via network analysis. Journal of Abnormal Psychology, 126(8), 1044-1056.

Fjorback, L. O., Arendt, M., Ornbøl, E., Fink, P. \& Walach, H. (2011). Mindfulness-based stress reduction and mindfulness-based cognitive therapy: a systematic review of randomized controlled trials. Acta Psychiatrica Scandinavica, 124(2), 102-119.

Fredrickson, B. L. (2001). The role of positive emotions in positive psychology: The broadenand-build theory of positive emotions. The American Psychologist, 56(3), 218-226.

Fredrickson, B. L. \& Joiner, T. (2018). Reflections on Positive Emotions and Upward Spirals [Review of Reflections on Positive Emotions and Upward Spirals]. Perspectives on 
Psychological Science: A Journal of the Association for Psychological Science, 13(2), 194-199.

Gates, K. M., Chow, S-M., Molenaar, P. C. M. (in press). Analysis of intra-individual variation: Systems approach to human processing. Chapman \& Hall/CRC. London.

Gates, K. M. \& Molenaar, P. C. M. (2012). Group search algorithm recovers effective connectivity maps for individuals in homogeneous and heterogeneous samples. Neurolmage, 63(1), 310-319.

Greenberg, L. S. (2010). Emotion-Focused Therapy: A Clinical Synthesis. FOCUS, 8(1), 3242.

Hayes, S. (2019). A Liberated Mind: The essential guide to ACT. Random House.

Hayes, S. C., \& Hofmann, S. G. (2018). Process-Based CBT: The Science and Core Clinical Competencies of Cognitive Behavioral Therapy. New Harbinger Publications.

Hayes, S. C., Hofmann, S. G. \& Ciarrochi, J. (2020a). A process-based approach to psychological diagnosis and treatment: The conceptual and treatment utility of an extended evolutionary meta model. Clinical Psychology Review, 82, 101908.

Hayes, S., Hofmann, S., Ciarrochi, J. (2020b). Building a Process-Based Diagnostic System: An Extended Evolutionary Approach. In Hayes S \& Hofman (Ed.), Beyond the DSM (pp. 251-278). New Harbinger Publications.

Hayes, S. C., Hofmann, S. G., Ciarrochi, J., Chin, F. T., \& Baljinder, S. (2020, December). How change happens: What the world's literature on the mediators of therapeutic change can teach us. Evolution of Psychotherapy Conference.

Hayes, S. C., Hofmann, S. G. \& Stanton, C. E. (2020). Process-based functional analysis can help behavioral science step up to novel challenges: COVID - 19 as an example. Journal of Contextual Behavioral Science, 18, 128-145.

Hayes, S. C., Hofmann, S. G., Stanton, C. E., Carpenter, J. K., Sanford, B. T., Curtiss, J. E. \& Ciarrochi, J. (2019). The role of the individual in the coming era of process-based therapy. Behaviour Research and Therapy, 117(September), 40-53.

Hayes, S. C., Merwin, R. M., McHugh, L., Sandoz, E. K., A-Tjak, J. G. L., Ruiz, F. J., Barnes- 
Holmes, D., Bricker, J. B., Ciarrochi, J., Dixon, M. R., Fung, K. P.-L., Gloster, A. T., Gobin, R. L., Gould, E. R., Hofmann, S. G., Kasujja, R., Karekla, M., Luciano, C. \& McCracken, L. M. (2021). Report of the ACBS Task Force on the strategies and tactics of contextual behavioral science research. Journal of Contextual Behavioral Science, 20, 172-183.

Hayes, S. C., Strosahl, K. \& Wilson, K. G. (1999). Acceptance and Commitment Therapy: An experiential approach to behavior change. The Guilford Press.

Hofmann, S. G., Asnaani, A., Vonk, I. J. J., Sawyer, A. T. \& Fang, A. (2012). The Efficacy of Cognitive Behavioral Therapy: A Review of Meta-analyses. Cognitive Therapy and Research, 36(5), 427-440.

Hofmann, S. G., Curtiss, J. E. \& Hayes, S. C. (2020). Beyond linear mediation: Toward a dynamic network approach to study treatment processes. Clinical Psychology Review, 76,101824 .

Hofmann, S. G. \& Hayes, S. C. (2019). The Future of Intervention Science: Process-Based Therapy. Clinical Psychological Science, 7(1), 37-50.

Hofmann, S. G., Hayes, S. C. \& Lorscheid, D. N. (2021). Learning process-based therapy: A skills training manual for targeting the core processes of psychological change in clinical practice. New Harbinger Publications.

Insel, T., Cuthbert, B., Garvey, M., Heinssen, R., Pine, D. S., Quinn, K., Sanislow, C. \& Wang, P. (2010). Research domain criteria (RDoC): toward a new classification framework for research on mental disorders. The American Journal of Psychiatry, 167(7), 748-751.

Kanter, J. W., Manos, R. C., Bowe, W. M., Baruch, D. E., Busch, A. M. \& Rusch, L. C. (2010). What is behavioral activation? A review of the empirical literature. Clinical Psychology Review, 30(6), 608-620.

Kini, V. \& Ho, P. M. (2018). Interventions to Improve Medication Adherence: A Review [Review of Interventions to Improve Medication Adherence: A Review]. JAMA: The Journal of the American Medical Association, 320(23), 2461-2473. jamanetwork.com. 
Kupfer, D. J., First, M. B. \& Regier, D. A. (2002). A Research Agenda for DSM V. American Psychiatric Pub.

Kursa, M. B., Rudnicki, W. R. \& Others. (2010). Feature selection with the Boruta package. Journal of Statistical Software, 36(11), 1-13.

Ljótsson, B., Hedman, E., Mattsson, S. \& Andersson, E. (2017). The effects of cognitivebehavioral therapy for depression are not falling: A re-analysis of Johnsen and Friborg (2015) [Review of The effects of cognitive-behavioral therapy for depression are not falling: A re-analysis of Johnsen and Friborg (2015)]. Psychological Bulletin, 143(3), 321-325. psycnet.apa.org.

Maitland, D. W. M. (2015). Functional analytic psychotherapy compared to watchful waiting for enhancing social connectedness: A randomized clinical trial with a diagnosed sample (S. Gaynor (ed.)) [Western Michigan University]. https://www.proquest.com/dissertations-theses/functional-analytic-psychotherapycompared/docview/1725105829/se-2

Moffitt, T. E., Caspi, A., Taylor, A., Kokaua, J., Milne, B. J., Polanczyk, G. \& Poulton, R. (2010). How common are common mental disorders? Evidence that lifetime prevalence rates are doubled by prospective versus retrospective ascertainment. Psychological Medicine, 40(6), 899-909.

Molenaar, P. C. M. (2004). A Manifesto on Psychology as Idiographic Science: Bringing the Person Back into Scientific Psychology, This Time Forever. Measurement: Interdisciplinary Research and Perspectives, 2(4), 201-218.

Molenaar, P. C. M. (2013). On the necessity to use person-specific data analysis approaches in psychology. The European Journal of Developmental Psychology, 10(1), 29-39.

Mullins-Sweatt, S. N., Lengel, G. J. \& DeShong, H. L. (2016). The Importance of Considering Clinical Utility in the Construction of a Diagnostic Manual. Annual Review of Clinical Psychology, 12, 133-155.

Neacsiu, A. D., Rizvi, S. L. \& Linehan, M. M. (2010). Dialectical behavior therapy skills use 
as a mediator and outcome of treatment for borderline personality disorder. Behaviour Research and Therapy, 48(9), 832-839.

Neumann, J. V. (1932). Proof of the Quasi-Ergodic Hypothesis. Proceedings of the National Academy of Sciences of the United States of America, 18(1), 70-82.

Nezlek, J. B. (2012). Multilevel modeling analyses of diary-style data. In M. R. Mehl (Ed.), Handbook of research methods for studying daily life , (pp (Vol. 676, pp. 357-383). The Guilford Press, xxvii.

Nezu, A. M. \& Nezu, C. M. (2001). Problem Solving Therapy. Journal of Psychotherapy Integration, 11(2), 187-205.

Rabinowitz, A. R., \& Fisher, A. J. (2020). Person-Specific Methods for Characterizing the Course and Temporal Dynamics of Concussion Symptomatology: A Pilot Study. Scientific Reports, 10(1), 1248.

Richter, D., Wall, A., Bruen, A. \& Whittington, R. (2019). Is the global prevalence rate of adult mental illness increasing? Systematic review and meta-analysis. Acta Psychiatrica Scandinavica, 140(5), 393-407.

Ryan, R. M. \& Deci, E. L. (2017). Self-Determination Theory: Basic Psychological Needs in Motivation, Development, and Wellness. Guilford Publications.

Ryan, R. M. \& Frederick, C. (1997). On energy, personality, and health: subjective vitality as a dynamic reflection of well-being. Journal of Personality, 65(3), 529-565.

Sanford, B. (2021). An idionomic network analysis of psychological processes and outcomes (S. C. Hayes (ed.)) [Ph.D.]. University of Nevada, Reno.

Tsai, M., Kohlenberg, R. J., Kanter, J. W., Kohlenberg, B., Follette, W. C. \& Callaghan, G. M. (2009). A Guide to Functional Analytic Psychotherapy: Awareness, Courage, Love, and Behaviorism (1st ed.) [PDF]. Springer, Boston, MA.

Vaidyanathan, U., Morris, S., Wagner, A., Sherrill, J., Sommers, D., Garvey, M. \& Others. (2020). The nimh research domain criteria project: A decade of behavior and brai $n$ integration for translational research. Beyon D the DSM: Toward a Process-Based Alternative for Diagnosis and Mental Health Treatmen T, 23-46. 
Ware, J. E., Jr \& Sherbourne, C. D. (1992). The MOS 36-item short-form health survey (SF36). I. Conceptual framework and item selection. Medical Care, 30(6), 473-483.

Wells, A. (2008). Metacognitive Therapy: Cognition Applied to Regulating Cognition. Behavioural and Cognitive Psychotherapy, 36(6), 651-658.

Wells, A. \& Colbear, J. S. (2012). Treating posttraumatic stress disorder with metacognitive therapy: a preliminary controlled trial. Journal of Clinical Psychology, 68(4), 373-381.

Young, Q.-R., Ignaszewski, A., Fofonoff, D. \& Kaan, A. (2007). Brief screen to identify 5 of the most common forms of psychosocial distress in cardiac patients: validation of the screening tool for psychological distress. The Journal of Cardiovascular Nursing, 22(6), $525-534$.

Young, Q.-R., Nguyen, M., Roth, S., Broadberry, A. \& Mackay, M. H. (2015). Single-item measures for depression and anxiety: Validation of the Screening Tool for Psychological Distress in an inpatient cardiology setting. European Journal of Cardiovascular Nursing: Journal of the Working Group on Cardiovascular Nursing of the European Society of Cardiology, 14(6), 544-551. 
Supplementary materials: Full output from Baruta machine learning analysis 
Table S1: Ratings of importance for predictors of sadness

\begin{tabular}{|c|c|c|c|c|c|c|}
\hline Item & $\begin{array}{l}\text { Mean } \\
\text { Import }\end{array}$ & $\begin{array}{l}\text { Median } \\
\text { Import }\end{array}$ & $\begin{array}{l}\text { Min } \\
\text { Import }\end{array}$ & $\begin{array}{l}\text { Max } \\
\text { Import }\end{array}$ & Hits & Decision \\
\hline StruggleToConnectMoments & 20.17 & 20.22 & 18.03 & 22.34 & 1 & Confirmed \\
\hline NoOutletForFeelings & 18.76 & 18.66 & 16.84 & 20.57 & 1 & Confirmed \\
\hline StuckUnableChange & 18.49 & 18.54 & 15.91 & 21.24 & 1 & Confirmed \\
\hline ThinkingGotInWay & 13.83 & 13.76 & 10.28 & 16.06 & 1 & Confirmed \\
\hline Complying & 8.7 & 8.61 & 6.82 & 10.57 & 1 & Confirmed \\
\hline NoMeaningfulChallenge & 8.56 & 8.51 & 6.04 & 10.65 & 1 & Confirmed \\
\hline StruggledToKeepDoing & 8.44 & 8.5 & 6.42 & 10.77 & 1 & Confirmed \\
\hline HurtHealth & 7.87 & 7.84 & 5.65 & 9.97 & 1 & Confirmed \\
\hline HurtConnect & 7.73 & 7.76 & 5.52 & 9.65 & 1 & Confirmed \\
\hline ConnectToPeople & 6.72 & 6.71 & 4.35 & 8.77 & 0.99 & Confirmed \\
\hline Personallmpor & 5.38 & 5.39 & 2.77 & 7.63 & 0.96 & Confirmed \\
\hline UsedWhatLearned & 5.37 & 5.41 & 2.85 & 7.5 & 0.96 & Confirmed \\
\hline HelpHealth & 5.21 & 5.3 & 2.9 & 7.99 & 0.94 & Confirmed \\
\hline ThinkingHelpedLife & 3.59 & 3.62 & 1.58 & 5.37 & 0.73 & Confirmed \\
\hline StuckToStrategies & 3.5 & 3.63 & 0.46 & 5.93 & 0.77 & Confirmed \\
\hline ImportantChallenge & 2.92 & 3.02 & 0.4 & 5.98 & 0.57 & Confirmed \\
\hline PaidAttTolmportant & 2.75 & 2.73 & 0.8 & 4.53 & 0.59 & Rejected \\
\hline AbleToChangeBehavior & 2.6 & 2.66 & -0.3 & 4.76 & 0.47 & Rejected \\
\hline StuckToWhatCared & 2.52 & 2.55 & -0.08 & 4.77 & 0.47 & Confirmed \\
\hline ExperienceRangeEmotions & 2.27 & 2.2 & 0.38 & 4.42 & 0.43 & Confirmed \\
\hline ChangedEnvironment & 1.51 & 1.61 & -0.8 & 3.38 & 0.15 & Rejected \\
\hline
\end{tabular}

Note: Importance ratings varied across a maximum of 100 runs, due to variation in shadow(randomized) features and order of variable entry into each decision tree. Hit $=$ Percentage of times item recorded higher importance than the highest shadow feature. Confirmed features are considered to be predictive of the outcome. 
Table S2: Ratings of importance for predictors of anxiety

\begin{tabular}{|c|c|c|c|c|c|c|}
\hline Item & $\begin{array}{l}\text { Mean } \\
\text { Import }\end{array}$ & $\begin{array}{l}\text { Median } \\
\text { Import }\end{array}$ & $\begin{array}{l}\text { Min } \\
\text { Import }\end{array}$ & $\begin{array}{l}\text { Max } \\
\text { Import }\end{array}$ & Hits & Decision \\
\hline StruggleToConnectMoments & 21.92 & 21.92 & 20.15 & 24.36 & 1 & Confirmed \\
\hline NoOutletForFeelings & 18.2 & 18.25 & 16.08 & 20.26 & 1 & Confirmed \\
\hline StuckUnableChange & 15.94 & 15.88 & 13.33 & 18.04 & 1 & Confirmed \\
\hline ThinkingGotInWay & 12.73 & 12.71 & 10.72 & 15.5 & 1 & Confirmed \\
\hline StruggledToKeepDoing & 10.46 & 10.45 & 7.93 & 12.79 & 1 & Confirmed \\
\hline HurtHealth & 9.63 & 9.66 & 6.46 & 11.75 & 1 & Confirmed \\
\hline NoMeaningfulChallenge & 7.92 & 7.94 & 5.74 & 9.85 & 1 & Confirmed \\
\hline HurtConnect & 7.86 & 7.99 & 5.09 & 10.06 & 1 & Confirmed \\
\hline Complying & 7.56 & 7.52 & 4.02 & 9.71 & 1 & Confirmed \\
\hline HelpHealth & 6.08 & 6.13 & 3.18 & 7.96 & 1 & Confirmed \\
\hline ImportantChallenge & 5.04 & 5.03 & 2.95 & 6.9 & 0.96 & Confirmed \\
\hline StuckToStrategies & 4.17 & 4.19 & 1.48 & 6.3 & 0.91 & Confirmed \\
\hline PaidAttTolmportant & 4.1 & 4.07 & 0.65 & 6.38 & 0.89 & Confirmed \\
\hline StuckToWhatCared & 3.91 & 3.86 & 1.67 & 6.36 & 0.84 & Confirmed \\
\hline ExperienceRangeEmotions & 3.81 & 3.84 & 1.2 & 5.95 & 0.85 & Confirmed \\
\hline ConnectToPeople & 3.39 & 3.35 & 0.34 & 5.64 & 0.75 & Confirmed \\
\hline ThinkingHelpedLife & 3.3 & 3.37 & 0.87 & 6.46 & 0.73 & Confirmed \\
\hline Personallmpor & 2.8 & 2.89 & 0.42 & 5.24 & 0.55 & Rejected \\
\hline UsedWhatLearned & 2.74 & 2.71 & 0.23 & 5.31 & 0.6 & Rejected \\
\hline AbleToChangeBehavior & 2.67 & 2.7 & 0.13 & 4.86 & 0.59 & Confirmed \\
\hline ChangedEnvironment & 2.52 & 2.51 & -0.31 & 5.07 & 0.51 & Rejected \\
\hline
\end{tabular}

Note: Importance ratings varied across a maximum of 100 runs, due to variation in shadow(randomized) features and order of variable entry into each decision tree. Hit $=$ Percentage of times item recorded higher importance than the highest shadow feature. Confirmed features are considered to be predictive of the outcome. 
Table S3: Ratings of importance for predictors of anger

\begin{tabular}{|c|c|c|c|c|c|c|}
\hline Item & $\begin{array}{l}\text { Mean } \\
\text { Import }\end{array}$ & $\begin{array}{l}\text { Median } \\
\text { Import }\end{array}$ & $\begin{array}{l}\text { Min } \\
\text { Import }\end{array}$ & $\begin{array}{l}\text { Max } \\
\text { Import }\end{array}$ & Hits & Decision \\
\hline StruggleToConnectMoments & 19.32 & 19.28 & 17.28 & 21.23 & 1 & Confirmed \\
\hline StuckUnableChange & 17.16 & 17.16 & 15.15 & 19.44 & 1 & Confirmed \\
\hline NoOutletForFeelings & 16.85 & 16.94 & 14.29 & 18.45 & 1 & Confirmed \\
\hline HurtConnect & 12.62 & 12.62 & 10.16 & 14.97 & 1 & Confirmed \\
\hline HurtHealth & 10.02 & 9.95 & 8.53 & 12.03 & 1 & Confirmed \\
\hline ThinkingGotInWay & 9.47 & 9.51 & 7.13 & 11.97 & 1 & Confirmed \\
\hline Complying & 8.95 & 8.97 & 6.35 & 11.88 & 1 & Confirmed \\
\hline NoMeaningfulChallenge & 8.42 & 8.39 & 5.97 & 10.56 & 1 & Confirmed \\
\hline StruggledToKeepDoing & 7.23 & 7.24 & 4.44 & 9.8 & 1 & Confirmed \\
\hline ConnectToPeople & 6.34 & 6.37 & 3.69 & 8.64 & 0.99 & Confirmed \\
\hline UsedWhatLearned & 6.09 & 5.99 & 3.3 & 8.19 & 0.99 & Confirmed \\
\hline PaidAttTolmportant & 4.53 & 4.63 & 1.81 & 7.9 & 0.87 & Confirmed \\
\hline ThinkingHelpedLife & 4.48 & 4.59 & 1.46 & 6.27 & 0.88 & Confirmed \\
\hline Personallmpor & 3.99 & 3.95 & 1.41 & 6.57 & 0.84 & Confirmed \\
\hline ImportantChallenge & 3.51 & 3.56 & 1.31 & 5.99 & 0.7 & Confirmed \\
\hline ChangedEnvironment & 2.72 & 2.78 & 0.34 & 5.66 & 0.54 & Confirmed \\
\hline AbleToChangeBehavior & 2.63 & 2.71 & 0.25 & 5.07 & 0.51 & Rejected \\
\hline StuckToWhatCared & 2.5 & 2.45 & -0.98 & 5.55 & 0.44 & Confirmed \\
\hline HelpHealth & 2.49 & 2.52 & 0.11 & 4.8 & 0.44 & Rejected \\
\hline ExperienceRangeEmotions & 1.96 & 2.11 & -1.07 & 4.36 & 0.39 & Rejected \\
\hline StuckToStrategies & 1.57 & 1.72 & -1.78 & 3.44 & 0.11 & Rejected \\
\hline
\end{tabular}

Note: Importance ratings varied across a maximum of 100 runs, due to variation in shadow(randomized) features and order of variable entry into each decision tree. Hit $=$ Percentage of times item recorded higher importance than the highest shadow feature. Confirmed features are considered to be predictive of the outcome. 
Table S4. Ratings of importance for predictors of stress

\begin{tabular}{|c|c|c|c|c|c|c|}
\hline Item & $\begin{array}{l}\text { Mean } \\
\text { Import }\end{array}$ & $\begin{array}{l}\text { Median } \\
\text { Import }\end{array}$ & $\begin{array}{l}\text { Min } \\
\text { Import }\end{array}$ & $\begin{array}{l}\text { Max } \\
\text { Import }\end{array}$ & Hits & Decision \\
\hline StruggleToConnectMoments & 19.44 & 19.45 & 17.74 & 21.81 & 1 & Confirmed \\
\hline StuckUnableChange & 16.35 & 16.43 & 14.09 & 18.57 & 1 & Confirmed \\
\hline ThinkingGotInWay & 15.78 & 15.77 & 13.78 & 18.29 & 1 & Confirmed \\
\hline NoOutletForFeelings & 14.36 & 14.41 & 12.58 & 15.6 & 1 & Confirmed \\
\hline StruggledToKeepDoing & 12.16 & 12.03 & 9.52 & 15.29 & 1 & Confirmed \\
\hline HurtConnect & 9.78 & 9.75 & 7.05 & 11.51 & 1 & Confirmed \\
\hline Complying & 9.49 & 9.55 & 7.34 & 11.66 & 1 & Confirmed \\
\hline NoMeaningfulChallenge & 7.89 & 7.81 & 6.32 & 9.68 & 1 & Confirmed \\
\hline HurtHealth & 7.04 & 7.07 & 4.81 & 9.55 & 1 & Confirmed \\
\hline HelpHealth & 5.91 & 5.86 & 3.63 & 9.52 & 1 & Confirmed \\
\hline AbleToChangeBehavior & 4.64 & 4.65 & 2.43 & 6.8 & 0.96 & Confirmed \\
\hline ThinkingHelpedLife & 4.1 & 4 & 1.59 & 6.12 & 0.94 & Confirmed \\
\hline ExperienceRangeEmotions & 4.06 & 3.93 & 2.03 & 6.69 & 0.92 & Confirmed \\
\hline StuckToStrategies & 3.78 & 3.87 & 0.89 & 6.61 & 0.85 & Confirmed \\
\hline PaidAttTolmportant & 3.7 & 3.82 & 0.16 & 5.7 & 0.88 & Confirmed \\
\hline UsedWhatLearned & 3.49 & 3.47 & 1.66 & 5.64 & 0.82 & Confirmed \\
\hline StuckToWhatCared & 3.32 & 3.33 & 0.5 & 6.03 & 0.83 & Confirmed \\
\hline ChangedEnvironment & 3.14 & 3.11 & 0.67 & 6 & 0.79 & Confirmed \\
\hline ConnectToPeople & 3.02 & 3.1 & 1.11 & 5.54 & 0.7 & Confirmed \\
\hline ImportantChallenge & 2.69 & 2.68 & 0.33 & 5.03 & 0.62 & Confirmed \\
\hline Personallmpor & 2.19 & 2.29 & -0.94 & 4.93 & 0.47 & Rejected \\
\hline
\end{tabular}

Note: Importance ratings varied across a maximum of 100 runs, due to variation in shadow(randomized) features and order of variable entry into each decision tree. Hit $=$ Percentage of times item recorded higher importance than the highest shadow feature. Confirmed features are considered to be predictive of the outcome. 
Table S5. Ratings of importance for predictors for lack of support

\begin{tabular}{|c|c|c|c|c|c|c|}
\hline Item & $\begin{array}{l}\text { Mean } \\
\text { Import }\end{array}$ & $\begin{array}{l}\text { Median } \\
\text { Import }\end{array}$ & $\begin{array}{l}\text { Min } \\
\text { Import }\end{array}$ & $\begin{array}{l}\text { Max } \\
\text { Import }\end{array}$ & Hits & Decision \\
\hline StuckUnableChange & 20 & 20 & 17.71 & 22.02 & 1 & Confirmed \\
\hline NoOutletForFeelings & 16.98 & 16.94 & 15.21 & 19.09 & 1 & Confirmed \\
\hline StruggleToConnectMoments & 15.11 & 15.09 & 12.53 & 17.02 & 1 & Confirmed \\
\hline HurtConnect & 14.99 & 14.99 & 13.14 & 16.76 & 1 & Confirmed \\
\hline ThinkingGotInWay & 14.83 & 14.93 & 12.91 & 17.3 & 1 & Confirmed \\
\hline StruggledToKeepDoing & 11.86 & 11.83 & 9.89 & 13.98 & 1 & Confirmed \\
\hline Complying & 9.56 & 9.6 & 7.29 & 11.47 & 1 & Confirmed \\
\hline NoMeaningfulChallenge & 8.99 & 9.07 & 6.67 & 11.34 & 1 & Confirmed \\
\hline HurtHealth & 8.8 & 8.81 & 6.68 & 11.2 & 1 & Confirmed \\
\hline ConnectToPeople & 8.48 & 8.44 & 5.83 & 10.89 & 1 & Confirmed \\
\hline UsedWhatLearned & 7.32 & 7.21 & 5.33 & 9.23 & 1 & Confirmed \\
\hline ThinkingHelpedLife & 5.44 & 5.43 & 2.97 & 7.32 & 0.98 & Confirmed \\
\hline PaidAttTolmportant & 4.54 & 4.59 & 2.36 & 6.69 & 0.95 & Confirmed \\
\hline ImportantChallenge & 4.24 & 4.34 & 2.16 & 6.58 & 0.95 & Confirmed \\
\hline Personallmpor & 4.21 & 4.23 & 2.51 & 6.45 & 0.9 & Confirmed \\
\hline StuckToWhatCared & 3.83 & 3.94 & 0.42 & 6.77 & 0.84 & Confirmed \\
\hline HelpHealth & 3.59 & 3.65 & 1.07 & 6.17 & 0.76 & Confirmed \\
\hline ExperienceRangeEmotions & 3.57 & 3.45 & 0.93 & 5.94 & 0.8 & Confirmed \\
\hline ChangedEnvironment & 3.31 & 3.29 & 0.29 & 6.32 & 0.66 & Rejected \\
\hline StuckToStrategies & 2.88 & 2.88 & 0.24 & 5.53 & 0.58 & Confirmed \\
\hline AbleToChangeBehavior & 2.03 & 2.24 & -0.8 & 4.03 & 0.27 & Rejected \\
\hline
\end{tabular}

Note: Importance ratings varied across a maximum of 100 runs, due to variation in shadow(randomized) features and order of variable entry into each decision tree. Hit $=$ Percentage of times item recorded higher importance than the highest shadow feature. Confirmed features are considered to be predictive of the outcome. 
Table S6: Ratings of importance for predictors of vitality

\begin{tabular}{|c|c|c|c|c|c|c|}
\hline Item & $\begin{array}{l}\text { Mean } \\
\text { Import }\end{array}$ & $\begin{array}{l}\text { Median } \\
\text { Import }\end{array}$ & $\begin{array}{l}\text { Min } \\
\text { Import }\end{array}$ & $\begin{array}{l}\text { Max } \\
\text { Import }\end{array}$ & Hits & Decision \\
\hline HelpHealth & 14.64 & 14.6 & 13.25 & 16.2 & 1 & Confirmed \\
\hline ImportantChallenge & 13.29 & 13.48 & 11.71 & 14.64 & 1 & Confirmed \\
\hline ThinkingHelpedLife & 12.4 & 12.44 & 10.56 & 14.51 & 1 & Confirmed \\
\hline AbleToChangeBehavior & 11.7 & 11.62 & 10.61 & 13.81 & 1 & Confirmed \\
\hline ChangedEnvironment & 10.1 & 10.18 & 8.18 & 11.55 & 1 & Confirmed \\
\hline PaidAttTolmportant & 8.07 & 8 & 6.55 & 9.35 & 1 & Confirmed \\
\hline StruggleToConnectMoments & 7.7 & 7.59 & 5.62 & 9.65 & 1 & Confirmed \\
\hline NoMeaningfulChallenge & 7.53 & 7.54 & 4.81 & 9.55 & 1 & Confirmed \\
\hline ThinkingGotInWay & 7.07 & 6.98 & 5.67 & 9.89 & 1 & Confirmed \\
\hline Personallmpor & 7.04 & 7.16 & 4.83 & 8.55 & 1 & Confirmed \\
\hline StuckToStrategies & 6.48 & 6.53 & 3.89 & 8.41 & 1 & Confirmed \\
\hline StruggledToKeepDoing & 6.31 & 6.39 & 3.62 & 7.83 & 1 & Confirmed \\
\hline StuckUnableChange & 6.24 & 6.28 & 4.52 & 8.71 & 1 & Confirmed \\
\hline Complying & 5.82 & 5.7 & 3.58 & 8.22 & 1 & Confirmed \\
\hline UsedWhatLearned & 5.68 & 5.76 & 3.24 & 7.41 & 0.97 & Confirmed \\
\hline NoOutletForFeelings & 5.28 & 5.12 & 3.35 & 6.76 & 1 & Confirmed \\
\hline StuckToWhatCared & 5 & 5.03 & 3.33 & 6.59 & 0.97 & Confirmed \\
\hline ConnectToPeople & 4.5 & 4.55 & 2.4 & 6.47 & 0.95 & Confirmed \\
\hline HurtConnect & 3.8 & 3.97 & 0.9 & 5.1 & 0.86 & Confirmed \\
\hline HurtHealth & 3.53 & 3.42 & 1.31 & 5.82 & 0.78 & Confirmed \\
\hline ExperienceRangeEmotions & 3.42 & 3.62 & 1.68 & 5.05 & 0.81 & Confirmed \\
\hline
\end{tabular}

Note: Importance ratings varied across a maximum of 100 runs, due to variation in shadow(randomized) features and order of variable entry into each decision tree. Hit $=$ Percentage of times item recorded higher importance than the highest shadow feature. Confirmed features are considered to be predictive of the outcome. 
Table S7: Ratings of importance for predictors of health

\begin{tabular}{|c|c|c|c|c|c|c|}
\hline Item & $\begin{array}{l}\text { Mean } \\
\text { Import }\end{array}$ & $\begin{array}{l}\text { Median } \\
\text { Import }\end{array}$ & $\begin{array}{l}\text { Min } \\
\text { Import }\end{array}$ & $\begin{array}{l}\text { Max } \\
\text { Import }\end{array}$ & Hits & Decision \\
\hline HelpHealth & 13.22 & 13.21 & 11.53 & 15.59 & 1 & Confirmed \\
\hline StuckUnableChange & 13.2 & 13.13 & 10.98 & 15.7 & 1 & Confirmed \\
\hline AbleToChangeBehavior & 8.41 & 8.34 & 6.29 & 11.02 & 0.99 & Confirmed \\
\hline StuckToStrategies & 5.99 & 5.98 & 3.66 & 8.14 & 0.97 & Confirmed \\
\hline NoMeaningfulChallenge & 5.7 & 5.75 & 3.49 & 7.76 & 0.99 & Confirmed \\
\hline HurtHealth & 5.69 & 5.71 & 3.85 & 8.52 & 0.98 & Confirmed \\
\hline ChangedEnvironment & 5.66 & 5.7 & 3.04 & 8.37 & 0.99 & Confirmed \\
\hline ThinkingHelpedLife & 5.47 & 5.53 & 3.52 & 8.18 & 0.98 & Confirmed \\
\hline StruggledToKeepDoing & 4.86 & 4.72 & 3.1 & 6.89 & 0.96 & Confirmed \\
\hline ThinkingGotInWay & 4.71 & 4.73 & 2.53 & 6.47 & 0.93 & Confirmed \\
\hline ImportantChallenge & 4.54 & 4.53 & 1.9 & 6.39 & 0.96 & Confirmed \\
\hline StruggleToConnectMoments & 4.07 & 4.05 & 1.86 & 6.5 & 0.88 & Confirmed \\
\hline Complying & 3.59 & 3.57 & 1.22 & 5.83 & 0.86 & Confirmed \\
\hline UsedWhatLearned & 3.16 & 3.12 & 1.1 & 6.06 & 0.69 & Confirmed \\
\hline NoOutletForFeelings & 3.15 & 3.03 & 0.99 & 4.93 & 0.78 & Confirmed \\
\hline ExperienceRangeEmotions & 2.62 & 2.79 & -0.76 & 5.34 & 0.59 & Rejected \\
\hline HurtConnect & 2.61 & 2.7 & -0.08 & 5.19 & 0.53 & Rejected \\
\hline PaidAttTolmportant & 2.51 & 2.47 & -0.09 & 4.89 & 0.56 & Confirmed \\
\hline StuckToWhatCared & 2.39 & 2.52 & -0.48 & 5.04 & 0.56 & Rejected \\
\hline ConnectToPeople & 1.46 & 1.46 & -0.46 & 3.64 & 0.04 & Rejected \\
\hline Personallmpor & 1.26 & 1.25 & -0.04 & 2.94 & 0.02 & Rejected \\
\hline
\end{tabular}

Note: Importance ratings varied across a maximum of 100 runs, due to variation in shadow(randomized) features and order of variable entry into each decision tree. Hit $=$ Percentage of times item recorded higher importance than the highest shadow feature. Confirmed features are considered to be predictive of the outcome. 